\title{
A Review of Advanced Composite and Nanostructured Coatings by Solid-state Cold Spraying Process
}

\author{
Wenya Li 1,*, Hamid Assadi ${ }^{2}$, Frank Gaertner ${ }^{3}$, Shuo Yin 4 \\ ${ }^{1}$ State Key Laboratory of Solidification Processing, Shaanxi Key Laboratory of Friction Welding Technologies, \\ School of Materials Science and Engineering, Northwestern Polytechnical University, Xi'an 710072, PR China \\ ${ }^{2}$ Bruel Centre for Advanced Solidifcation Technology, Institue of Materials and Manufacturing, Brunel \\ University London, Kingston Lane, Uxbridge, UB8 3PH, UK \\ ${ }^{3}$ Mechanical Engineering, Helmut Schmidt University, University of the Federal Armed Forces Hamburg, \\ D-22043 Hamburg, Germany \\ ${ }^{4}$ Trinity College Dublin, The University of Dublin, Department of Mechanical and Manufacturing Engineering, \\ Parsons Building, Dublin 2, Ireland \\ * Corresponding: liwy@ nwpu.edu.cn (W.Y. Li); Tel.: +86-29-88495226; Fax: +86-29-88492642
}

\begin{abstract}
Cold spraying (CS) has been widely explored over the last decade due to its low process temperature and limited thermal effect on spray materials. As a solid-state process, the inherent deficiencies of traditional thermal spraying such as oxidation, decomposition and grain growth are avoided. This article summarizes the research work on the fabrication of composites and nanostructured coatings by the promising CS process. After a brief introduction to CS and its deposition mechanisms, the preparation methods of spray powders are classified. Different methods are appropriate for particles of various properties, and the tendency is to design composite powders by combined methods in order to create coatings with specified properties. Then the co-deposition mechanism of composite particles as well as research findings on metal-metal, metal-ceramic and metal-intermetallic composite coatings are reviewed concerning the deposition characteristics, microstructure and its relation to properties. Moreover, CS has been used to deposit a variety of nanostructured materials, including metals, metal-ceramic composites, and even ceramics, retaining their nanocrystalline nature in the coating without grain growth or phase transformation. Finally, the potential applications of CS and issues to be addressed in coating deposition are discussed.
\end{abstract}

Keywords: Cold spraying; Composite powder; Process parameters; Composite coatings; Nanostructured coatings

\section{Table of Contents}

1. Introduction. 2

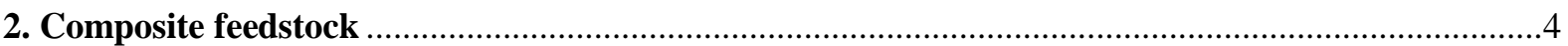

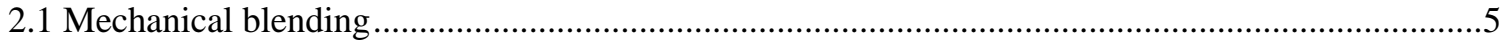

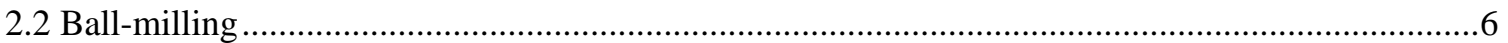

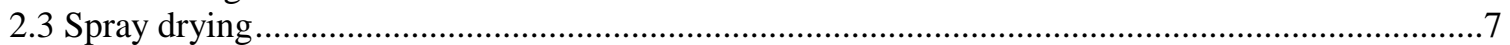

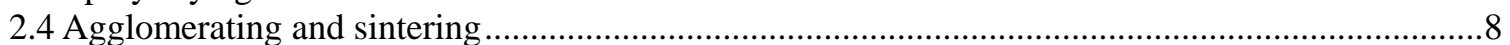

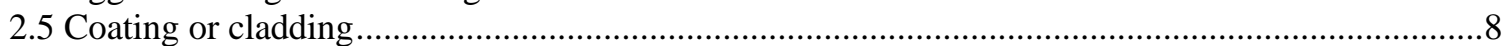

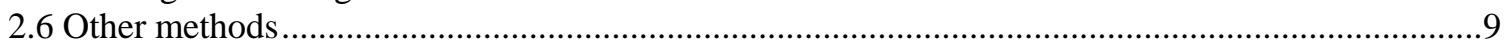




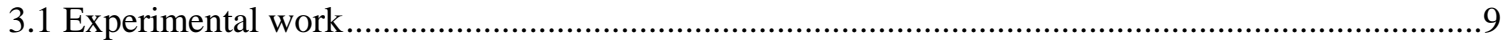

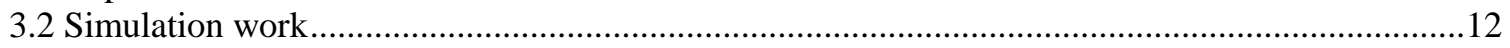

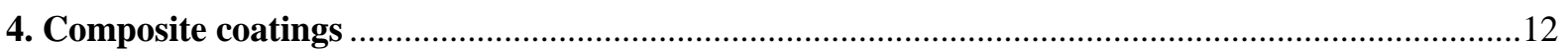

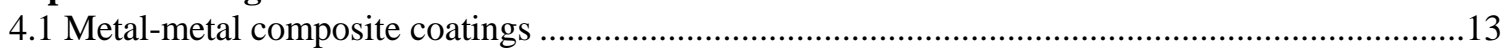

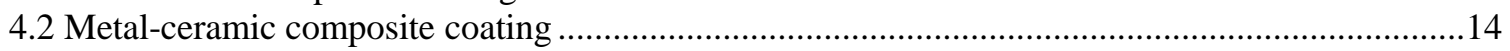

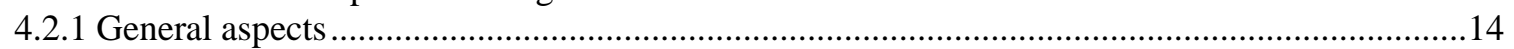

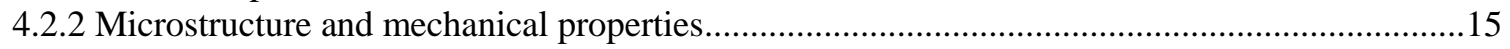

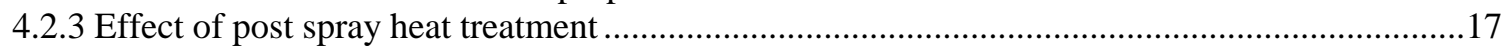

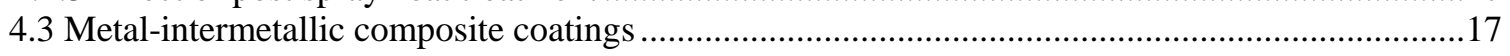

4.3.1 Formation by post spray heat treatment of cold-sprayed metal-metal composites.........................17

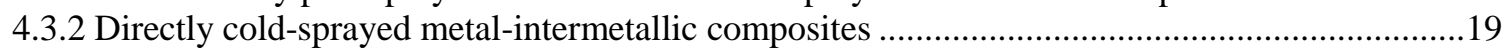

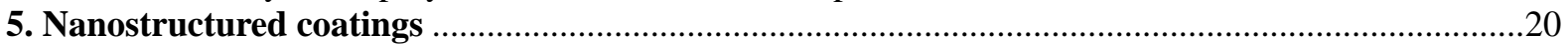

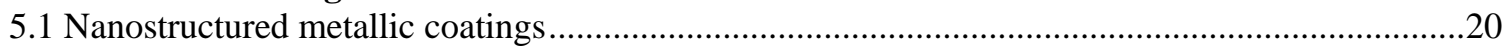

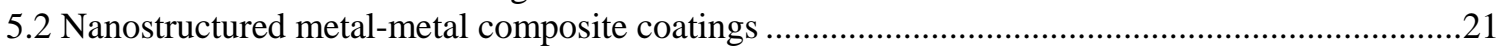

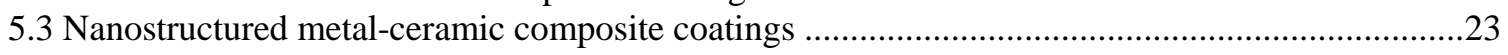

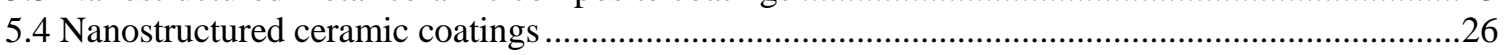

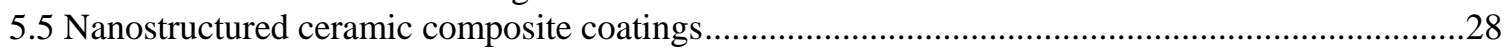

6. Potential applications of composite or nanostructured coatings ...................................................28

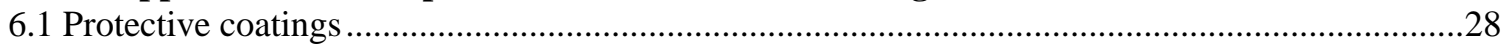

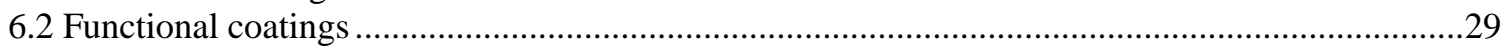

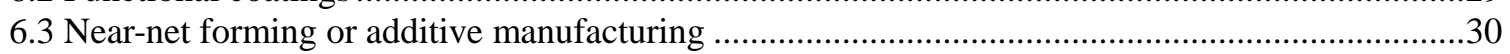

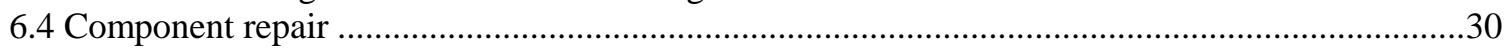

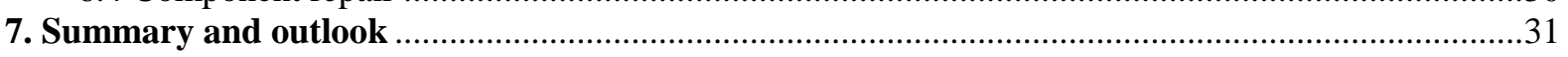

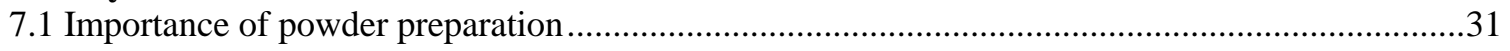

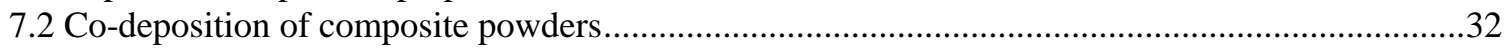

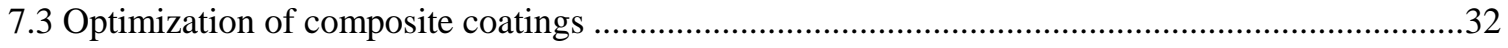

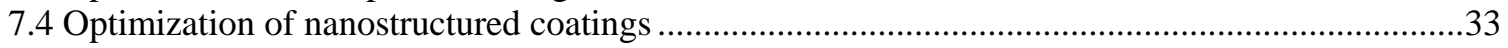

Funding

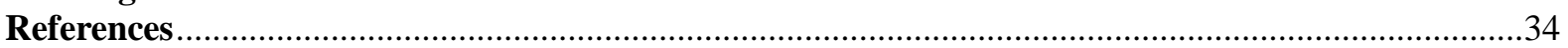

\section{Introduction}

Cold spraying (CS) is a relatively new solid-state coating technique based on supersonic fluid dynamics and high-speed impact dynamics. ${ }^{1,2}$ The cold spray system basically consists of a compressed gas delivery system, a gas heater, a powder feeder, a supersonic de-Laval nozzle, a robot arm, and an operation system as schematized in Figure 1a. ${ }^{3}$ High-temperature compressed propulsive gas passes through a de-Laval nozzle, generating a supersonic flow inside and outside the nozzle. The sprayed powder particles commonly in a size range of 5-50 $\mu \mathrm{m}$ are then realized in front of the nozzle inlet and accelerated to a high velocity ranging usually from 300 to $1200 \mathrm{~m} / \mathrm{s}$ by the supersonic jet and projected onto a substrate or a previously deposited coating in a nominally solid state, ${ }^{3,4}$ i.e. at a temperature well below the melting point of the powder. CS was originally developed in the mid-1980s at the Institute of Theoretical and Applied Mechanics of the Russian Academy of Science in Novosibirsk by Papyrin and his colleagues. ${ }^{4}$ They successfully deposited a wide range of pure metals, metal alloys, and composites onto a variety of substrate materials. A U.S. patent was issued in 1994, with a European one in 1995. Following these, CS has drawn worldwide attention, promting numereous experimental and theoretical studies, especially in the last decade..$^{5-10}$ 
Thermal spraying (TS) was primarily used to produce coatings or thin films before the invention of CS. However, as a fusion-based technology TS coatings gerneally suffer from weark coaing-substrate interfacial bonding, high porosity, high oxidation and possible negative impact on the underneath substrate. ${ }^{11} \mathrm{CS}$ features higher particle velocity and lower processing temperature (see Figure 1b), producing a series of advantages compared to TS. For example, there are limited heat effects on substrates and spray powders. The oxidation, decomposition, phase transformation and grain growth of the spray materials or substrates can be avoided, allowing the deposition of phase transformation sensitive materials (e.g. nanostructured materials, ${ }^{12-14}$ amorphous materials, ${ }^{15-19}$ and WC-Co ${ }^{20-22}$ ) and oxidation sensitive materials (e.g. $\mathrm{Cu}^{23,24} \mathrm{Al}^{25,26} \mathrm{Ti}^{1,27-30}$ ). In addition, the resulting residual stresses are normally relatively low and mostly compressive compared to $\mathrm{TS},{ }^{31,32}$ which permits the deposition of thick coatings. Thus, considering its characteristics of high deposition efficiency (DE), high deposition rate, recyclable feedstock, together with no need for high temperature heat source, CS is an economical technique.

As for the bonding mechanisms of metallic particles in CS, much work has been done in the last decade. The widely accepted hypothesis on the bonding process is that the high velocity impact of particles induces intensive plastic deformation at the interface enabling a bond to be formed, as shown in Figure 2, i.e. metallurgical or metallic bonding. ${ }^{36-46}$ This holds true even for the cases where the substrates are ceramics or glasses, ${ }^{47,48}$ where the deformation will totally occur within the particles. The second issue is that how strong the metallurgical bonding is or how significant is the contribution of metallurgical bonding to the final adhesion or cohesion, as compared to the so-called mechanical interlocking effect in TSed coatings. ${ }^{48-55}$ The third question concerns the possible localised interface melting and its effect on adhesion. ${ }^{56-61}$ The fourth issue is how submicron- or nano-sized ceramic particles are bonded in some circumstances. ${ }^{62,63}$ The literature contains brief reviews on these questions, e.g., by Hussain. ${ }^{37}$ Nevertheless, no matter which mechanism controls the bonding, there should be enough bonding strength to prevent the rebounding force, i.e., a critical velocity is needed to provide enough deformation and clean interfaces. ${ }^{24}$ Several important factors influence the critical velocity, i.e. materials properties, ${ }^{4,36,37}$ particle surface oxidation ${ }^{50,64-66}$ and particle/substrate temperature. ${ }^{39,64,67-73}$ The process parameters that influence these factors will affect the coating deposition. ${ }^{6,73-87}$

Up to now, CS has been used to fabricate a variety of coatings, including mostly elemental metals and alloys, but also composite coatings, providing corrosion resistance,,$^{26,88-93}$ wear resistance ${ }^{21,94-96}$ and high temperature resistance,,$^{97-99}$ as well as functional coatings ${ }^{100-108}$ for industrial applications. The detailed microstructure evolution in CS coatings have been reviewed by some researchers, e.g. Lee and Kim ${ }^{109}$ and Borchers et al. ${ }^{24}$. 
Apart from coating deposition applications, ${ }^{110}$ additive manufacturing with CS (also called Cold Gas Dynamic Manufacturing $(\mathrm{CGDM})^{111,112}$ ) has also been proposed based on its low processing temperature, high DE and controllable spray print. By this method, components can be fabricated with relatively complex shapes from dissimilar materials, while retaining the inherent materials properties, having great potential in rapid prototyping and component restoration, which may even overturn the traditional fabrication and restoration techniques. It is worth noting that the U.S. Department of Defense has approved a military standard (MIL-STD-3021) in 2008 on coating fabrication and repair of components, ${ }^{113}$ and that the U.S. Patent and Trademark Office has granted a number of patents, e.g. US20110129351A1 for the deposition of a protective strip onto the leading edge of a composite airfoil. ${ }^{114}$ Recently, CS has been added into the current additive manufacturing process families, as defined by the "Standard Terminology for Additive Manufacturing Technologies", which is part of the ASTM F2792-12A standard series. ${ }^{115}$

In the majority of industrial applications, coatings consisting of a single material may not fully meet difficult specifications such as high wear and corrosion resistance, excellent chemical stability, while composites, which combine the properties of different components, can be useful. In particular, compared to traditional composite fabrication technologies, such as powder metallurgy (PM), pressure infiltration, ${ }^{116}$ spark plasma sintering, ${ }^{117}$ in-situ reaction spraying and thermal spraying, friction stir processing, ${ }^{118} \mathrm{CS}$ does not possess deleterious effects of interface reaction, oxidation, and under-utilization of the reinforcement phase ${ }^{119,120}$. Therefore, CS shows great potential in the fabrication of composite coatings. Furthermore, many techniques have been explored to fabricate nanocrystalline materials, e.g. inert gas condensation, precipitation from solution, mechanical alloying, rapid solidification, and crystallization from amorphous phases. ${ }^{121}$ However, it is very difficult to produce large-area nanocrystalline metallic films or large volume bulk nano metallic materials used in structures. The key point lies in avoiding grain growth and oxidation in order to retain the nanostructure of metallic materials, and CS does show great potential because of its low processing temperature.

Since Shukla et al. first studied a CS nanostructured WC-10Co coating in the year $2000^{20}$ and Ti- 25 vol.\% nano-hydroxyapatite (HA) composite coating in 2001, ${ }^{122}$ a number of articles on composite coatings, including metal-metal, metal-ceramic and metal-intermetallic composite coatings, as well as nanostructured coatings have been published. This paper mainly summarizes the important aspects related to the deposition characteristics of composite and nanostructured coatings by CS to enlighten its further applications.

\section{Composite feedstock}

Three methods can be used to deposit a composite coating. The first commonly used method is to prepare the 
composite powders before spraying; ${ }^{123,124}$ the second one is to mix powders during spraying, e.g. using two or more powder feeders; ${ }^{125}$ the third one is to make the composites by post-spray treatment, e.g. heat treatment, ${ }^{97,98}$ laser surface remelting ${ }^{126}$ or friction stir processing ${ }^{127,128}$, possibly with additives. This section focuses on the pre-prepared composite powders for CS.

It is a well-known fact that powder preparation is very important before spraying. Well-prepared powders contribute to the increase of deposition efficiency and favourable modification of coating microstructures. Besides, it is possible to develop high performance coatings through powder design. As per the CS process requirements on high deposition efficiency and stability of powder feeder, the size of powder is commonly in a size range of 5-50 $\mu \mathrm{m}$, while the powder morphology prefers round-shaped particles.

Powder preparation for composite powders includes the selection of a matrix phase and a reinforcement phase, as well as the production methods. Generally speaking, mechanical blending, ball-milling, spray drying, agglomerating and sintering, coating or cladding are mainly employed to process composite powders. Different methods have their merits and downsides in terms of powder feeding, volume fraction and distribution of reinforcement particles, and interfacial bonding between the matrix and reinforcement in the coatings (see Table 1). The main considerations and challenges that need to be addressed in powder preparation are as follows.

\subsection{Mechanical blending}

Mechanical blending or mixing is a very simple process that has been widely used in previous studies due to its ease of operation, i.e., to put the powder mixture in a bottle and blend it manually or by a mixer. For instance, Wang et al. ${ }^{129}$ mechanically blended spherical $\mathrm{Al}$ (mean particle size of $10 \mu \mathrm{m}$ ) with $\mathrm{Al}_{2} \mathrm{O}_{3}$ (mean particle size of $20 \mu \mathrm{m}$ ) in a mixer to prepare $\mathrm{Al}_{-} \mathrm{Al}_{2} \mathrm{O}_{3}$ composite feedstock (Figure 3a). Yandouzi et al. ${ }^{130}$ mixed $\mathrm{Al12} \mathrm{Si}$ (5-65 $\mu \mathrm{m}$ ) and $\mathrm{SiC}$ (9-44 $\mu \mathrm{m})$ powders with different ceramic contents (Figure 3b). Li et al. ${ }^{94}$ mechanically mixed gas atomized Al2319 powder $(5-63 \mu \mathrm{m})$ with irregular TiN powder $(10-45 \mu \mathrm{m})$ for CS, and Yu et al. ${ }^{76,131}$ also used this method to produce Al5056-SiC composite powder. Besides metal-ceramic mixtures, some researchers mixed two or more metals for some special applications, e.g. $\mathrm{Al} / \mathrm{Zn},{ }^{132} \mathrm{Al} / \mathrm{Cu},{ }^{51} \mathrm{~W} / \mathrm{Cu},{ }^{77}$ and $\mathrm{Cu} / \mathrm{Ni} / \mathrm{Al}^{133}$.

Although it is relatively easy and very inexpensive, it cannot ensure adequate uniformity of the mixed powders. In addition, the differences in particle density, size or morphology between the mixed ingredients will result in various ranges of particle velocities, and thus various deposition efficiencies, which may lead to significant deviation of the coating composition from that of the starting powders. ${ }^{76,134}$ Furthermore, because the reinforcement is distruibted at the interfaces of the deformed matrix particles in this method, the distribution of reinforcement seems relatively nonuniform, especially when the matrix particles are relatively large. Nevertheless, if the matrix and reinforcement 
particles are both fine, the distribution seems acceptable.

\subsection{Ball-milling}

The ball-milling method can avoid the shortcomings of mechanical blending as it is based on the cold-welding and crushing effects of the balls to refine the ingredient materials, ${ }^{135}$ producing finer and more homogeneous powders for mixtures. In this way, one can control the content, size and distribution of the two phases, and thus control the composition of the coatings. It is very important for use.

It has been reported that ball-milling parameters including milling speed, time and atmosphere have a significant influence on powder morphology and coating quality. ${ }^{136} \mathrm{Li}$ et al. ${ }^{119}$ milled A15356 and TiN powder in a planetary ball mill (Figure 4a). Zhang et al. ${ }^{137}$ applied this method to produce Ni-Al composite powder with the atom ratio of 1:1. Yandouzi et al. ${ }^{138}$ ball-milled $\mathrm{Al}-12 \mathrm{Si}$ and $\mathrm{B}_{4} \mathrm{C}$ mixture in a liquid nitrogen atmosphere (cryomilled) (Figure 4b). Besides, Wang et al..${ }^{97}$ Kang et al. ${ }^{139}$ and Tria et al. ${ }^{140}$ also used the ball-milling method to produce Fe-Al, W-Cu and Ni-Ti composite powders, respectively. It is clear that all the ball-milled powders produce better mixtures and bonds, and thus a better coating. Li et al. ${ }^{119}$ deposited TiN reinforced Al5356 coatings with the feedstocks prepared with both ball-milling and mechanical-blending as shown in Figure 5. It was found that the ball-milled powder yields a denser and homogeneous coating with super fine TiN particles dispersed into the A15356 matrix, leading to a higher microhardness due to the "constraint effect" of ceramic particulates on the deformation of the soft $\mathrm{Al}$ matrix.

Recently, Luo et al. ${ }^{141}$ reported a novel ball-milling based method for powder preparation. They ball-milled 20 vol.\% Co powder and 80 vol.\% WC-10Co powder to produce a core-shelled structured WC-Co powder as shown in Figure 6. The WC-10Co cores were covered with Co-rich WC-75Co shells of a thickness of 3-6 $\mu \mathrm{m}$, in which the WC particle sizes are in a submicron range (Figure 6b). Therefore, the outer layer has higher deformability than the hard core, and the coating deposited by this kind of feedstock has improved fracture toughness compared to that by pure WC-10Co powder. ${ }^{141}$

The ball-milling method is also an effective way to produce nanostructured feedstocks. In certain cases, the milling process is carried out in a liquid nitrogen atmosphere (called cryomilling) in order to lower the ductility of the metallic powders and to avoid the formation of small flakelets that are very difficult to feed. Li et al. ${ }^{142}$ milled Fe and Si powders in a planetary mill in ethanol for various times to produce nanocrystalline powders as shown in Figure 7a. The Si peaks almost disappeared after 32h, at the the same time the broadening of Fe (110) peak could be clearly observed. This fact suggests the formation of a nanocrystalline structure in the milled powder as evidenced by the TEM analysis (Figure 7b). Wang et al. ${ }^{143}$ milled Fe and Al powders in a high-energy 
ball mill in an argon atmosphere to produce composite powders with a composition corresponding to $\mathrm{Fe}_{60} \mathrm{Al}_{40}$ (Figure 7c). Ajdelsztajn et al. ${ }^{144}$ cryomilled A15083 powders with ball-to-powder weight ratio of 32:1 to prepare nanocrystalline powder (Figure 7d). Richer et al., ${ }^{145}$ Ghelichi et al. ${ }^{146}$ and Zhang et al. ${ }^{147}$ prepared nanocrystalline Al-Mg alloy, Al7075and Al2009 feedstocks, respectively.

Few papers have focused on the effect of the ball-milling parameters on the resultant powders and the CS coatings. ${ }^{142}$ Woo et al. ${ }^{148}$ used the high-energy ball-milling method to produce nano-diamond-reinforced aluminum matrix composites powders. They found that by altering the ball-to-powder ratio and milling time, the particle size and shape, $\mathrm{Al}$ crystal size and residual strain, the structural integrity and dispersion of nano-particle inclusions can be controlled as indicated in Figure 8, which is a crucial requirement for subsequent CS powder consolidation.

In summary, ball milling is a good way to control the composition of the composite powder as well as that of the composite coating. The differences caused by the different ingredients will be eliminated because they will flight as "one" single composite particle. However, the mill parameters should be carefully selected to produce composite particles: (1) with a near-spherical shape, and (2) appropriate size range, for easy powder feeding. Sometimes, screening of milled powders should be conducted. This method is also cost-effective to make nanostructured powders, but careful control of milling process is necessary to produce particles of acceptable shapes, e.g in a liquid nitrogen atmosphere.

\subsection{Spray drying}

In spray drying, the ingredients are fully mixed with a liquid forming slurry, and then atomized and dried by hot gas, obtaining homogeneous composite powders with a near-spherical shape. Bakshi et al. ${ }^{149}$ applied this method to ensure a good dispersion of carbon nanotubes (CNTs) in a micron-sized gas-atomized Al-Si eutectic powder as shown in Figs. 9 (a, b). The spray-dried powders had a particle size of $57 \pm 21 \mu \mathrm{m}$, containing 5 wt.\% CNTs. Kang et al. ${ }^{139}$ spray-dried $\mathrm{Cu}-\mathrm{W}$ powder, which had already been ball-milled, to achieve better agglomerated W-Cu composite powder as shown in Figs. 9 (c, d), thus minimizing the effects of the large difference in density between $\mathrm{Cu}\left(8.96 \mathrm{~g} / \mathrm{cm}^{3}\right)$ and $\mathrm{W}\left(19.3 \mathrm{~g} / \mathrm{cm}^{3}\right)$, and ensuring homogeneous distribution of W in the CS W-Cu composite.

In addition, nano-particles normally need an agglomeration treatment before CS in order to form micron-sized particles, because it is very difficult to feed small particles, and they do not possess enough inertia to penetrate the bow shocks zone. ${ }^{21,150}$ This method has also been used to produce micron-sized particles for conventional powder feeders in thermal spraying. Hodder et al. ${ }^{151}$ agglomerated $20 \mathrm{~nm} \mathrm{Al}{ }_{2} \mathrm{O}_{3}$ powder to form porous particles 
with a size range from 2 to $10 \mu \mathrm{m}$ as shown in Figure 10a, then mechanically mixed them with pure $\mathrm{Al}$ at various weight ratios to form metal-ceramic composite feedstocks. Phani et al. ${ }^{152}$ agglomerated ball-milled nanocrystalline $\mathrm{Cu}-\mathrm{Al}_{2} \mathrm{O}_{3}$ powder to a size range of $22-45 \mu \mathrm{m}$ for $\mathrm{CS}$ as shown in Figure 10b. Kim et al. ${ }^{153,154}$ used an agglomerated nano-WC-12\%Co powder for CS as shown in Figure 10c. The powder after agglomeration is relatively spherical and compact, and the size of WC is in a range of $100-200 \mathrm{~nm}$. Similarly, Yandouzi et al. ${ }^{155}$ also deposited nanocrystalline WC-15Co coatings with a feedstock prepared by spray drying, but the coating quality is less than that by the sintered WC-Co powders.

In summary, spray drying is easy to produce homogeneous composite powders with a near-spherical shape ready for feeding, especially with nano-particles. However, it is worth to note that the used organic solvents may influence the hardness and wear resistance of the resultant coatings. ${ }^{156}$

\subsection{Agglomerating and sintering}

Powders made by spray drying usually have poor cohesion strength, requiring a post sintering treatment to avoid this defect. This method is mainly used in the fabrication of cermet powders for TS, e.g. WC-Co and $\mathrm{Cr}_{3} \mathrm{C}_{2}$-NiCr. The agglomerated and sintered powders usually present a spherical morphology with high volume fraction of micron-sized carbide particles embedded in the metallic Co binder (Figure 11a). ${ }^{155-157}$ For example, Wolfe et al. ${ }^{75}$ used a $\mathrm{Cr}_{3} \mathrm{C}_{2}-25 \mathrm{wt} . \% \mathrm{NiCr}$ powder prepared by agglomerating and sintering for $\mathrm{CS}$ as shown in Figure 11b.

The agglomerating and sintering method can also be used for nano-WC-Co powders. Li et al. ${ }^{158,159}$ agglomerated nano-sized WC with Co, which was then sintered. The powder produced had a size range from 5 to $44 \mu \mathrm{m}$, with the $\mathrm{WC}$ grain size in the range of $50-500 \mathrm{~nm}$ as shown in Figure 12.

In summary, besides the broader use in TS, agglomerating and sintering are very useful in making appropriate CS powders with spherical shapes and suitable size range. However, the production cost is a little high. In addition, this method has mainly been used in producing cermet powders. It would be very helpful if this method is used to produce other types of compsite powders.

\subsection{Coating or cladding}

Apart from the above commonly used methods, coating (or cladding) is also an effective way to produce composite powders. Generally, one metal is coated on a hard phase. By regulating the thickness of the coated layer, one can obtain powders with various volume fractions of the hard phase, and thus depositing a coating with a high and controlled volume fraction of the hard phase. $\mathrm{Li}$ et al. ${ }^{160,161}$ employed a $\mathrm{Ni}$-coated $\mathrm{Al}_{2} \mathrm{O}_{3}$ powder produced by the hydrothermal hydrogen reduction method in order to increase the volume fraction of ceramic particles in the 
deposited composite coating as shown in Figure 13a. The alumina particles are cladded with Ni particulates with a thickness of about $10-20 \mu \mathrm{m}$, thus the volume fraction of alumina in the coating can reach values as high as $29 \% .160$ Feng et al. ${ }^{162}$ deposited Ni coating on $\mathrm{B}_{4} \mathrm{C}$ particles by chemical vapor deposition (CVD) in order to prevent $\mathrm{B}_{4} \mathrm{C}$ fragmentation and promote $\mathrm{B}_{4} \mathrm{C}$ adhesion as shown in Figure 13b. Other combinations include Ni-coated diamond ${ }^{163}$ mixed with bronze and Ti-coated diamond mixed with $\mathrm{Fe}^{164}$, $\mathrm{Cu}$-coated diamond mixed with $\mathrm{Cu}$, ${ }^{165}$ to avoid the fracture of diamond particles and decrease the difference in mass between diamond and metallic particles at the same time. However, there may be a problem that the optimal thickness of the soft clad layer should be thick enough to successfully bond the hard phase but not too thick to lower the coating hardness. ${ }^{166}$

This method was originally used for TS powders. If it is used for CS, certain adjusting of the process is necessary to yield a suitable coat to optimize the coating properties. In addition, it is difficult to generate very fine particles, which is expected for particle acceleration in CS. Again, the cost of this method is relatively high.

\subsection{Other methods}

It should be noted that the combination of different powder preparation methods might be useful in powder design, and thus coating design. Kim et al. ${ }^{167}$ produced $\mathrm{TiB}_{2}-43$ vol. $\% \mathrm{Cu}$ nano-powders containing $\mathrm{TiB}_{2}$ particles $50-100$ $\mathrm{nm}$ in size as shown in Figure 14a, which was in-situ produced in a copper matrix using high-energy ball-milling of Ti, B and powders and self-propagating high-temperature synthesis. Yang et al. ${ }^{168}$ designed a bi-modal WC-12Co powder as shown in Figure 14b. The fabrication procedure uses at the beginning high-energy ball-milling of conventional WC-Co and nano WC particles, followed by sintering and crashing, then annealing at $1000^{\circ} \mathrm{C}$ in a hydrogen atmosphere to further modify the feedstock, producing a powder with both high hardness and high fracture toughness. Other methods, e.g. spray drying and simple mechanical blending, ${ }^{149}$ crushed grinding and sintering ${ }^{75}$ casting and crushing ${ }^{156}$, wet chemically synthesizing and agglomerating, ${ }^{169}$ all aim at acquiring a homogeneous feedstock and enhancing the deposition efficiency of the hard reinforcement phase. However, these combined methods will inevitably increase the cost.

In summary, a well-prepared powder would be beneficial to the tailoring of coating microstructure and properties. However, different methods have various pros and cons as summarized in Table 1. Even with combined methods, careful control of the powders is necessary.

\section{Co-deposition behavior and mechanism of metal-reinforcement consolidation}

\subsection{Experimental work}

In the case of composite powders, their deposition behavior is different from that of the deposition of metals as the reinforcement particles hardly deform upon impacting. The soft metal phase deforms significantly, acting as matrix, while the hard phase (hard metal or ceramic) embeds in the matrix, acting as reinforcement. An interesting 
experiment was performed by Shkodkin et al. ${ }^{85}$, where they sprayed pure $\mathrm{Al}$ on a steel substrate in one pass and simutaneously sprayed pure ceramic particles also in one pass but in a cross way with Al. It was found that a smooth thin Al layer was developed at the Al particle jet line, and steel erosion was found at the ceramic particle jet line, while the coating thickness increased linearly at their intersection position as shown in Figure 15a. This is the so-called "co-deposition". They attributed this interesting fact to the 'surface activation' effect of ceramic particles, i.e., the erosion effect of hard ceramics results in an increased substrate roughness and a clean active surface, which promotes the deposition of Al particles as indicated in Figure 15b. Coatings can only be seen at the left side, which had been gritted beforehand.$^{85}$ Lee et al. ${ }^{170,171}$ reported that it is easier to deposit a ceramic-soft metal $(\mathrm{Al}, \mathrm{Cu})$ mixture than pure $\mathrm{Al}$ or $\mathrm{Cu}$ metal or pure ceramic in low-pressure $\mathrm{CS}$ as shown in Figure 16. It should be pointed out that this is possibly true for low-pressure CS (with low DE), but not necessarily the case for high-pressure CS (with high DE). The thicknesses of pure $\mathrm{Al}$ and pure $\mathrm{SiC}$ coatings are about 30-40 $\mu \mathrm{m}$ and $4 \mu \mathrm{m}$, respectively, while that of composite coating can be as high as 80-100 $\mu \mathrm{m}$ under the same spray conditions. This fact is due to the addition of hard ceramic particles that produce many craters at the substrate surface before $\mathrm{Al}$ deposition. This is beneficial to $\mathrm{Al}$ adhesion, and the binder effect of soft metal in turn promotes the deposition of $\mathrm{SiC}$, similar to the observation by Shkodkin et al.$^{85}$. Grigoriev et al. ${ }^{166}$ and Sova et al. ${ }^{73,82,83}$ further pointed out that the addition of ceramics can lower the critical velocity for pure metals, and consequently "critical" temperature (the minimum gas stagnation temperature at which particles begin to adhere) necessary for spraying these metals, and the deposition efficiency also increases at the same time as indicated in Figure $17 .{ }^{166} \mathrm{~A}$ small fraction of ceramic powders $\left(\mathrm{Al}_{2} \mathrm{O}_{3}, \mathrm{SiC}\right)$ in the feedstock does produce a strong activation effect on the substrate surface and increases the deposition efficiency of the metal component in the mixture compared to spraying of pure metals. While a too large fraction of ceramic particles considerably hinders coating deposition because their erosion effect exceeds their activation effect. ${ }^{73,82}$

For the activation mechanism of ceramics, Grigoriev et al. ${ }^{166}$ further identified two mechanisms: (1) ceramic particles increase the substrate roughness, and (2) clean the oxide films from the substrate surface increasing their chemical/metallurgical activity as shown in Figure 18. They also proposed (3) the possible interactive effect of metal and ceramic particles during flight under a very high powder flow rate, which cleans away oxide films on the surface of metal particles and increases chemical/metallurgical activity, though this is not supported by experimental evidence. The traditional grit blasting is efficient in removing oxide films, but the surface morphology produced is possibly not optimal as compared to the in-situ activation with ceramic particles. Other approaches such as combination of ablation and laser heating do provide optimum surface topography and 
improve metallurgical activity, promoting intimate bonding between the coating and substrate. ${ }^{166,172}$

The deposition process mainly consists of the impact between metal and ceramic particles, the deformation of metal particles and the tamping effect of ceramic particles, ${ }^{85,88,129,173,174}$ so the co-deposition behavior between metal and ceramic phases can increase coating deposition efficiency and bonding strength..$^{91,129,175}$ However, the collision between ceramic particles at higher ceramic contents will become predominant and result in decreased deposition efficiency, since the deposition will still depend on the ductile metal due to the poor deformability of ceramic particles as shown in Figure 19. ${ }^{76,85,88,177-181}$ It is worth noting that the deposition efficiency increased in all cases with temperature, though the maximum deposition efficiency achieved was always for a ceramic content of about $30 \%$ for each temperature.$^{85}$ The mechanism responsible for this needs further exploration.

Additionally, it was found that the addition of hard phase (hard metal or ceramic) in the powder mixture can lower coating porosity and improve coating hardness due to their tamping effect during deposition as the extra kinetic energy of the hard phase promotes the deformation of the metal particles. ${ }^{137,182-184}$ The coating hardness increase is due to the increased strain hardening effect as well as the strengthening effect of ceramics. The microhardness of the as-sprayed TiN-reinforced composite coatings, as shown in Figure $20,{ }^{185}$ decreases remarkably after heat-treatment at different temperatures for $2 \mathrm{~h}$ due to recovery and/or recrystallization, but is still higher than that of pure Al coating. This fact clearly indicates that the uniformly dispersed hard particles significantly strengthen the matrix.

Moreover, the presence of hard phase allows the working gas to reach high temperatures without nozzle clogging or blocking, which in consequence improves the coating compactness as it increases particle deformation and bonding due to the thermal softening effect at elevated temperatures. ${ }^{182,183,186}$ The adhesion strength between the coating and the substrate as well as the cohesion strength of the coating itself can be increased to a certain degree as shown in Figure 21. The adhesion strength is mostly determined by the bond between metallic particles and substrate ${ }^{88}$ while the cohesion strength depends on the scale of deformation as well as the intimate contact area of metallic particles in the coating. ${ }^{131}$ The mechanical interlocking between ceramics and deformed metallic particles or the substrate can also affect in a positive way the bonding strength (Figure 21(a)). However, an excessively increased number of ceramic particles can decrease the contact area between the deformed particles, and thus the cohesion strength will decrease at the same time as shown in Figure 21(b). The coating shear strength is affected in a similar way. ${ }^{129}$

Recently, to identify the strengthening mechanisms of hard particles in CSed composites, Huang and $\mathrm{Li}^{187}$ designed an experimental method to qualitatively calculate the proportions of different strengthening effects on 
the microhardness as shown in Figure 22. By comparing the microhardness of the as-sprayed and heat-treated TiNp/A15356 coatings deposited with different TiN fractions (Figure 22a), two strengthening mechanisms of TiN particles in composite coatings were identified, i.e. the strain-hardening effect of TiN particles tamping on the Al5356 matrix and the dispersion strengthening effect of uniformly dispersed TiN particles (Figure 22b, also see Figure 20). The dispersion strengthening effect of TiN particles plays a greater role in microhardness increment than the strain-hardening effect of TiN tamping the Al5356 matrix. In addition, with the increase of TiN fraction in the coating, the microhardness increment induced by both effects rise. High resolution TEM analysis indicated that an intimate contact is formed at the TiNp/Al5356 interface. However, some cracks and pores around the TiN particle can be found at the interface, and the bonding is still relatively weak. ${ }^{187}$

\subsection{Simulation work}

Bearing in mind the above findings, Assadi et al. ${ }^{188}$ and Yu et al. ${ }^{184}$ tried to understand some important aspects during the depositon of composite/inhomogernous particles by numerical simulations. Although it is just on the beginning, some results are interesting. Assadi et al. ${ }^{188}$ found that for a hard-core/soft-shell particle (i.e., a ceramic core coated by a metal layer), as shown in Figure 23, the shell thickness had some influence on particle deposition. The rupture of the shell and detachment of the hard core becomes evident when the shell thickness is decreased from 2 to $1 \mu \mathrm{m}$. By further decreasing the shell thickness to $0.5 \mu \mathrm{m}$, there is also a jump in the maximum stress level. Since the core does not deform plastically, the same amount of kinetic energy must be dissipated via plastic deformation of the shell, regardless of the shell thickness. This means that for a smaller shell thickness, the deformation work would be higher. A higher deformation could in turn result in rupture and detachment, especially for complex deformation patterns as brought about by inhomogeneous material properties.

Yu et al. ${ }^{184}$ also found the similar result, as shown in Figure 24. The plastic deformation of the Al5056 particles was increased due to the non-deformation of In718 particle. In other words, all the kinetic energy of the In718 particle is transferred as the additional deformation of the neighboring Al5056 particles. Thus, it is understandable that the addition of In718 improves the compactness of the Al5056 coating as the experiment shows. ${ }^{184}$

To better understand the underlying mechanism, a better simulation model and smart procedure are necessary.

\section{Composite coatings}

Composite coatings produced by CS can be either of metal-metal, of metal-ceramic, or of metal-intermetallic type. The research findings on the composite coating microstructure and properties are accordingly summarized in term of 
these three types, rather than the elemental materials.

\subsection{Metal-metal composite coatings}

The metal-metal composite coatings are mainly applied in the circumstances that normally need a high thermal conductivity, where corrosion resistance is required, or in sputtering targets. Examples follow:

(1) Heat sinks in electronic packages require high conductivity and low coefficient of thermal expansion, making the W-Cu composite a good candidate. ${ }^{139}$

(2) The addition of $\mathrm{Al}$ in $\mathrm{Zn}$ coatings can increase greatly the coating lifetime when used as a sacrificial layer for protecting the substrate materials from corrosion. ${ }^{90,189}$

(3) A Ni-Cr composite can be used as oxidation resistant coating. ${ }^{99}$

(4) A Cu-In composite can be used as a sputtering target. ${ }^{190}$

(5) A Cu-Cr coating can be used as an electrical contact material for its excellent electrical conductivity, high breaking current capability, and high resistance to electric arc corrosion and surface fusion welding. ${ }^{191}$

CS can deposit blended elemental metal powders with two or more components to produce metal-metal composite coatings with a dense structure, in a relatively easier and economic way compared to thermal spraying. ${ }^{139,192}$ Further to these, there is no reaction or phase transformation during the CS process, and the deposited materials can be easily machined to the expected shapes before forming intermetallic compounds via post-spray heat treatment, and preserving the functional integrity of each component. ${ }^{90,192}$ For example, during CS Al/Zn mixture, severely deformed $\mathrm{Al}$ particles act as a dense matrix phase, while the slightly deformed $\mathrm{Zn}$ particles are homogeneously distributed in the $\mathrm{Al}$ matrix. ${ }^{193}$ Other articles have focused on various combinations, e.g. Ti-Al, ${ }^{192} \mathrm{Fe}-\mathrm{Al},{ }^{97} \mathrm{~W}-\mathrm{Cu},{ }^{139} \mathrm{Ni}-\mathrm{Al},{ }^{98,195,196} \mathrm{Cu}-\mathrm{Cr},{ }^{191} \mathrm{Al}-\mathrm{Co}-\mathrm{Ce},{ }^{194} \mathrm{Ni}-\mathrm{Ti},{ }^{140}$ and even bronze-quasicrystal $(\mathrm{AlCuFeB})^{197}$. Typical cross sections of metal-metal composite coatings are shown in Figure 25. It is clear that one material is embedded in or surrounded by the other one, forming a compact structure with limited porosity and uniformly distributed hard particles, indicating the dense feature of CS coatings.

Compared to traditional processing methods, metal-metal composite coatings made with CS may possess excellent corrosion and oxidation resistance because of the dense structure. For example, Bala et al. ${ }^{99}$ deposited $\mathrm{Ni}-20 \mathrm{Cr}$ and $\mathrm{Ni}-50 \mathrm{Cr}$ coatings on boiler steels with CS, where the coatings showed a dense microstructure with porosity less than $1.9 \%$. The coatings also showed higher hardness than the substrate steel without discernible oxidation. High temperature oxidation tests at $900^{\circ} \mathrm{C}$ showed that $\mathrm{Ni}-20 \mathrm{Cr}$ and $\mathrm{Ni}-50 \mathrm{Cr}$ coatings reduced the weight gain of the steel by $84 \%$ and $93 \%$, respectively. They also found that the $\mathrm{Ni}-20 \mathrm{Cr}$ coating had excellent hot corrosion resistance in a $\mathrm{Na}_{2} \mathrm{SO}_{4}-60 \% \mathrm{~V}_{2} \mathrm{O}_{5}$ environment at $900^{\circ} \mathrm{C}$, reducing the weight gain of the steel by $87.2 \% .^{93}$ The 
dense, strongly adhered coatings block the penetration of corrosive species towards the substrate, and lower the corrosion rate of substrate. ${ }^{198,199}$ Zhao et al. ${ }^{90}$ used induction or laser to remelt the surface of a CS Zn-Al-Si composite coating. A protecting surface layer with gradient $\mathrm{Zn}$ concentration was formed with a gradient electrochemical potential, providing more effective protection from corrosion than a pure coating. Li et al. ${ }^{189}$ reported that the self-corrosion rate of CS $\mathrm{Zn}-50 \mathrm{Al}$ coating is lower than that of a $\mathrm{Zn}$ coating, thus providing a better protection for steel.

The other properties, e.g. electricity, are also increased. Kang et al. ${ }^{139}$ deposited the W-Cu mixture on a carbon steel substrate with $\mathrm{CS}$ and plasma spraying. There was no oxidation of $\mathrm{Cu}$ in the $\mathrm{CS}$ coating, while that produced with plasma spraying had a high concentration of copper oxides. Wu et al ${ }^{191}$ fabricated the $\mathrm{Cu}-15 \% \mathrm{Cr}$ coating with porosity, hardness and electrical resistivity of $0.24 \pm 0.04 \%, 232 \pm 7 \mathrm{HV}$, and $71.5 \pm 0.7 \%$ IACS, respectively, which are superior to those of the composites prepared with explosive compaction and meet industrial standards. Rolland et al. ${ }^{101}$ deposited an Ag-30\% Ni composite coating for electrical contacts, and durablity testing in industrial facilities showed that the erosion of CS contacts is lower than conventional PM ones.

\subsection{Metal-ceramic composite coating}

\subsubsection{General aspects}

Particle reinforced metal matrix composites (PRMMCs) combine the properties of metals (high strength and toughness) with those of ceramics (excellent wear resistance, corrosion resistance and chemical stability), increasing the service life of components. The preparation of PRMMCs has become one of research hot topics. However, it is difficult to fabricate high-performance PRMMC by conventional means, especially those with high volume fraction of ceramics. CS showed great potential in producing MMC coatings with metal matrices, such as $\mathrm{Al}$ and its alloys, ${ }^{76,88,894,95,119,120,127,129,131,138,179,180,200} \mathrm{Ni}$ and its alloys ${ }^{91,75,160-162,201}$ and $\mathrm{Cu}$ based composites, ${ }^{153,167,202}$ cermets $^{22,157,203}$ and other metal-ceramic coatings. The composite coatings are compact, have high microhardness and bonding strength, and are superior or comparable to traditional thermal sprayed (TSed) coatings.

Considering the high temperature in TS, it is not suitable for depositing metallic powders containing oxidization sensitive or phase transformation sensitive components. Here we take WC-Co for example. WC-Co coatings are widely used in wear resistant applications. The hard WC particles form the major wear resistant constituent, while the Co binder provides toughness. ${ }^{155}$ Thermal spraying of WC-Co coatings will inevitably generate the brittle $\eta$ phase and causedecarburization of WC, which severely affect their hardness and wear 
resistance. ${ }^{20,204}$ A simple comparasion on the WC-Co coatings deposited by both CS and TS is made (Table 2),

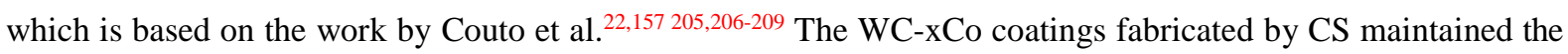
original phases of the particles, while the counterparts by high velocity oxy-fuel spraying (HVOF) or high velocity air-fuel spraying (HVAF) experienced decarbonization and formed hard brittle $\mathrm{W}_{2} \mathrm{C}, \mathrm{Co}_{6} \mathrm{~W}_{6} \mathrm{C}$ and $\mathrm{Co}_{3} \mathrm{~W}_{3} \mathrm{C}$ phases, which cause the coatings to possess a higher hardness but lower toughness. However, the CS coatings showed lower deposition efficiency and adhesion strength. The wear rate is in the same magnitude but the volume loss is much lower than that by HVOF or HVAF, which suggests an increased wear resistance. Moreover, the corrosion resistance of coatings by CS is increased by $8-37 \%$ than that by HVOF or HVAF due to its dense microstructure. ${ }^{22,157,205,206,210}$ Thus, apart from the low deposition efficiency, the coating properties by CS seem better than those by HVOF or HVAF.

\subsubsection{Microstructure and mechanical properties}

Typical cross-sections of a few CS metal-ceramic composite coatings are shown in Figure 26. All the coatings present a dense microstructure. The soft metals deform severely acting as matrix, while the ceramic particles remain undeformed acting as reinforcement. As shown in Figure 26d, an intimate interface was formed between $\mathrm{Al}$ and $\mathrm{Al}_{2} \mathrm{O}_{3}$, and severe plastic deformation of $\mathrm{Al}$ led to grain refinement, while no trace of deformation was observed at the $\mathrm{Al}_{2} \mathrm{O}_{3}$ side. ${ }^{211}$ Normally, the tamping effect of hard ceramics promotes the deformation of metal phase and enhances the coating desity and hardness.

Tables 3 and 4 summarize corrosion and wear behaviors of CS composite coatings. From Table 3, it can be concluded that the addition of ceramics has no negative effect on the coating corrosion behavior, e.g. the corrosion resistance of $\mathrm{Al}-\mathrm{Al}_{2} \mathrm{O}_{3}$ coatings is comparable to that of pure $\mathrm{Al}$ coating ${ }^{88}$ or bulk $\mathrm{Al}$ alloys ${ }^{95}$, and is independent of the ceramic content. ${ }^{95,179,200}$ For CS coatings, two factors will influence their corrosion behavior, the coating porosity and residual stresses. ${ }^{212}$ The reported increased corrosion resistance of the composite coating is due to the increased coating compactness. ${ }^{182,183}$ The addition of hard ceramics allows using a higher gas preheating temperature with no clogging, which increases the softening effect as well as the tamping effect of ceramics to produce compact structures. ${ }^{182,183,186}$ Moreover, post spray heat treatment (PSHT) can also increase corrosion resistance by relieving residual stresses, the elimination of defects through recovery and recrystallization, and the reduction of voids by rearranging grains. ${ }^{183,186,212}$ The wear performance of these composites, as indicated in Table 4, is improved with the addition of ceramic particles. The increased coating hardness as well as the effect of third-body abrasion by ceramic particles may decrease the coefficient of friction (COF) significantly and reduce the wear rate by an order of magnitude. ${ }^{22,94,119,160,213,214}$ as shown in Figure 
27. ${ }^{120,140}$ The decreased COF is becuase that the ceramic particles in the worn track change the wear mode from adhesion to abrasion..$^{95,181}$ The separated ceramic particles mix with the soft surface forming a strain-hardened layer, which protects the underlying coating and leads to the decreased wear rate. ${ }^{213-215}$ Nevertheless, there are exceptions, for example, Triantou et al. ${ }^{216}$ reported that for $\mathrm{CS} \mathrm{Cu}-\mathrm{A}_{2} \mathrm{O}_{3}$, the $\mathrm{COF}$ increased with increasing the content of $\mathrm{A}_{2} \mathrm{O}_{3}$. However, the wear rate decreased because the plastically deformed $\mathrm{Cu}$ and its oxides formed a protective layer. Thus, the effect of ceramics on COF and wear rate is material dependent. Typical wear surfaces of pure coating and composite coating are shown in Figure 28. The narrower worn track on the composite coating than the corresponding pure coating indicated that the addition of hard ceramics increases the wear resistance significantly. Furthermore, Li et al. ${ }^{161}$ and Xiao et al. ${ }^{202}$ found that the wear mechanism of coatings depends on ambient temperature. Sevillano et al. ${ }^{201}$ found that the $\mathrm{CS} \mathrm{Ni}-\mathrm{Al}_{2} \mathrm{O}_{3}$ coating exhibits good oxidation resistance even at $520^{\circ} \mathrm{C}$, and Heimann et al. ${ }^{217}$ reported a similar finding for $\mathrm{Al}-\mathrm{Al}_{2} \mathrm{O}_{3}$ composite.

The feedstocks for metal-ceramic composite coatings are mostly prepared with mechanical blending. Figure 29 summarizes the contents of ceramics in the mechanically blended feedstocks and their volume fractions in the final coatings. The slopes of three dotted lines in Figure 29 are 1, 0.7 and 0.3, which correspond to the percentages of ceramics in the coating to that in the feedstock are $100 \%, 70 \%$ and $30 \%$, respectively. We gave these values based on the observation that the content of $\mathrm{SiC}$ in the deposit is mainly $70-90 \%$ of that in the feedstock, while the value for $\mathrm{Al}_{2} \mathrm{O}_{3}$ is $30-70 \%$ with most contents of about $50 \%$, giving a relative deposition efficiency of $\mathrm{SiC}$ higher than $\mathrm{Al}_{2} \mathrm{O}_{3}$, except for the case of Al-12Si-SiC coating. It is also clear that the content of ceramics in the composite is generally lower than that in the feedstock because of their relatively different deposition efficiencies. However, at a low concentration, the fraction of ceramics in the coating may be higher than that in the feedstock due to the relavtiely high deposition efficiency of the reinforcement phase. ${ }^{176}$ It should be noted that the Al-TiN coating has the highest deposition efficiency with the comparable TiN retaining in the coating (even more in other powder blends ${ }^{94}$ ). These facts are possibly because (1) the different densities of TiN, $\mathrm{Al}_{2} \mathrm{O}_{3}$ and $\mathrm{SiC}$ of $5.2 \mathrm{~g} / \mathrm{cm}^{3}, 3.9 \mathrm{~g} / \mathrm{cm}^{3}$ and $3.2 \mathrm{~g} / \mathrm{cm}^{3}$, respectively, compared to the density of $\mathrm{Al}$ alloys, (2) the different relative deposition efficiencies of various materials in CS. ${ }^{65}$ Experiments clearly show that the fraction of ceramics can be controlled by adjusting feedstocks.

Figure 30 summarizes the findings for microhardness of composite coatings with the change of ceramic particles in the coatings. The coating hardness is higher than the corresponding pure $\mathrm{Al}$ or $\mathrm{Al}$ alloys, and it increases with $\mathrm{SiC}$ or $\mathrm{Al}_{2} \mathrm{O}_{3}$, which is due to the severe plastic deformation of the $\mathrm{Al}$ matrix and the tamping effect of hard ceramics. Uniformly dispersed ceramic particles also contribute to the increase of the coating 
hardness by restricting the deformation of soft $\mathrm{Al}$ matrix. ${ }^{218}$ It is worth noting that $\mathrm{Al}$ alloys based composite coatings show higher hardness than pure $\mathrm{Al}$ based coatings, because $\mathrm{Al}$ alloys is harder than pure $\mathrm{Al}$. Moreover, there is a strong dependency of hardness of $\mathrm{Al}$ alloys based coatings on ceramic content. The hardness of coatings reinforced by $\mathrm{SiC}$ is remarkably higher than that by $\mathrm{Al}_{2} \mathrm{O}_{3}$. In addition to matrix phase effects, the higher deposition efficiency of $\mathrm{SiC}$ compared to $\mathrm{Al}_{2} \mathrm{O}_{3}$ (Figure 31), together with the fact that $\mathrm{Al}-\mathrm{SiC}$ coatings show a more compact structure compared to $\mathrm{Al}-\mathrm{Al}_{2} \mathrm{O}_{3}$ coatings, may also account for the higher hardness.

Therefore, with these trends in mind, one can control the coating hardness and tribological properties by altering the type and content of ceramics in the feedstock.

Furthermore, it has been reported that the grain size in the $\mathrm{Al}$ matrix decreases with increasing $\mathrm{SiC}$ content, and smaller size $\mathrm{SiC}$ particulates improve refinement. In addition to this effect, aging response is sensitive to the reinforcement size ${ }^{219}$ Changing the reinforcement content in the metal matrix in a controlled manner, CS can accurately produce predictable changes in thermal properties like conduction and expansion. ${ }^{220}$

\subsubsection{Effect of post spray heat treatment}

Researchers have also studied other aspects of the metal-ceramic composite coatings. It has been found that PSHT can enhance the adhesion and compactness of the coating, ${ }^{185}$ but has little effect on size, morphology and distribution of ceramic particles. ${ }^{221}$ Zhou et al. ${ }^{212}$ found that PSHT can significantly improve corrosion and mechanical properties of CS HA-Ti coatings due to the annihilation of defects, porosity reduction and residual stress relief during PSHT. Watanabe et al. ${ }^{222}$ carried out four-point bending tests on WC-Co/Al multilayer composite coating, and found that the ductile metal phase is very effective in enhancing the toughness and damage tolerance of sprayed cermet coatings. Wang et al. ${ }^{211}$ used electron backscattered diffraction (EBSD) to characterize the $\mathrm{CS} \mathrm{Al}-\mathrm{Al}_{2} \mathrm{O}_{3}$ coating, to find anisotropic nano-mechanical properties due to the higher density of dislocations and grain boundaries on the cross plane formed during coating deposition. Heimann et al. ${ }^{217}$ reported that the $\mathrm{Al}-\mathrm{Al}_{2} \mathrm{O}_{3}$ coating states low thermal conductivity, low solar absorptance, comparatively high infrared emittance and oxidation stability, which can protect space-bound structures against deleterious effects of the space environment.

\subsection{Metal-intermetallic composite coatings}

\subsubsection{Formation by post spray heat treatment of cold-sprayed metal-metal composites}

Intermetallics possess the advantages of high melting point, high creep strength, low density, high oxidation resistance and corrosion resistance, which allow them to be used as high-temperature structural materials in aerospace industry. However, the intrinsic brittleness of intermetallics at room temperature makes it very 
difficult to directly deposit intermetallic particles. ${ }^{223}$ The studies are mainly about producing intermetallic reinforced MMCs with PSHT of as-cold-sprayed metal-metal composite coatings. $51,97,98,192,195,196,224-226$

Typical metal-intermetallic composite coatings prepared by CS and PSHT are summarized in Table 5. The work mainly covers $\mathrm{Ni}-\mathrm{Al}, \mathrm{Ti}-\mathrm{Al}$ and $\mathrm{Fe}-\mathrm{Al}$ intermetallics. In almost every case, feedstocks were prepared with ball-milling and the as-sprayed coatings were annealed in an inert atmosphere ( $\operatorname{Ar}$ or $\left.\mathrm{N}_{2}\right)$ at various times and temperatures. The following has been found:

(1) The intermetallics formed in the annealed $\mathrm{Ni}-\mathrm{Al}$ coating are mainly $\mathrm{Al}_{3} \mathrm{Ni}$ and $\mathrm{Al}_{3} \mathrm{Ni}_{2}$. The quantity of $\mathrm{Al}_{3} \mathrm{Ni}_{2}$ increases with temperature so as the hardness of the coating, which proves that intermetallics have a significant effect on coating hardness. ${ }^{98,195,196}$ In addition, pores were found in the annealed coating due to the Kirkendall effect. ${ }^{196}$ Zhang et al. ${ }^{137}$ also reported the $\mathrm{Al}_{3} \mathrm{Ni}_{2}$ phase in the ball-milled NiAl coating annealed at a low temperature, however, at a temperature higher than $850^{\circ} \mathrm{C}$ (above the melting point of $\mathrm{Al}$ ), the whole coating completely transformed to NiAl. The melting of $\mathrm{Al}$ will greatly facilitate the reaction diffusion of $\mathrm{Ni}$ atoms into $\mathrm{Al}$, besides the conventional solid-state atomic diffusion. Moreover, Podrabinnik et al. ${ }^{227}$ observed $\mathrm{AlNi}$ and $\mathrm{Al}_{3} \mathrm{Ni}_{2}$ intermetallics in laser annealed $\mathrm{CS} \mathrm{Al} / \mathrm{Al}_{2} \mathrm{O}_{3}-\mathrm{Ni}$ composite coating. The phase transformation from a Ni-Al composite to NiAl intermetallic can also result in closing non-bonded gaps in the coating at higher temperatures, ${ }^{228}$ but with the formation of pores by the Kirkendall effect.

(2) In the case of Ti-Al composite coatings, there is no significant reaction during the CS process. ${ }^{229} \mathrm{PSHT}$ also leads to the formation of intermetallic phases. By changing the heat-treatment condition, the desirable intermetallic phases can be formed, however, coating porosity also increases rapidly with time at elevated temperatures due to the Kirkendall effect. ${ }^{192}$ Kong et al. ${ }^{226}$ deposited the premixed Ti-Al powder with the molar ratio of $1: 3$, to produce a coating with a dense structure and a porosity of $0.17 \%$. After heat treatment at $650^{\circ} \mathrm{C}$ for $5 \mathrm{~h}$, there was phase transformation to form $\mathrm{TiAl}_{3}$ and an interlayer of $(\mathrm{Ti}, \mathrm{Nb}) \mathrm{Al}_{3}$ around $10 \mu \mathrm{m}$ was formed at the coating-substrate interface, and the porosity was increased to $14.69 \%$ due to the Kirkendall effect. Similarly, according to Ti-Al phase diagram, the contact melting of $\mathrm{Al}$ at $650^{\circ} \mathrm{C}$ will also facilitate the reaction diffusion of Ti atoms. Oxidation tests did indicate a good high-temperature oxidation resistance of the coating. Cizek et al. ${ }^{230}$ also confirmed the Kirkendall effect and the oxidation resistance of the $\mathrm{TiAl}_{3}$ coating. They further pointed out that the optimal PSHT temperature is $500-580^{\circ} \mathrm{C}$, where intermetallic phase formation is induced while Kirkendall pores are almost avoided at a relatively low temperature. Wang et al. ${ }^{231}$ fabricated a $\mathrm{TiAl}_{3}$ bond coat by CS together with PSHT for yttria partially stabilized zirconia (YSZ) thermal barrier coatings (TBC). A pure $\mathrm{Al}$ coating with a thickness about 40-60 $\mu \mathrm{m}$ was deposited on a $\gamma$-TiAl alloy, then heat 
treated at $700{ }^{\circ} \mathrm{C}$ for $12 \mathrm{~h}$ in $\mathrm{Ar}$, obtaining a dense $\mathrm{TiAl}_{3}$ coating with a thickness about $60-100 \mu \mathrm{m}$, thicker than as-sprayed Al coating, which is also facilitated by the melting and reaction diffusion. The surface of the formed $\mathrm{TiAl}_{3}$ bond coat permitted the deposition of a YSZ top coat, and subsequent high temperature oxidation test showed that this coating system improves the oxidation resistance of TiAl substrate.

(3) Wang et al. ${ }^{97,232}$ deposited Fe-Al composite coatings and XRD results showed that with increasing annealing temperature, the content of the intermetallic compound increases (Figure 32a). The differential scanning calorimetry (DSC) analysis showed that $\mathrm{Fe}_{2} \mathrm{Al}_{5}$ was the first intermetallic phase formed upon heating at $625^{\circ} \mathrm{C}$. The deposit transformed to mainly FeAl phase with a trace of remaining Fe phase as the temperature reached $900^{\circ} \mathrm{C}$, as indicated by XRD in Figure $32 \mathrm{~b}$. Note that the melting of $\mathrm{Al}$ under this condtion greatly facilitates the reaction diffusion of $\mathrm{Fe}$ atoms. It was found that the formation of $\mathrm{Fe}_{2} \mathrm{Al}_{5}$ intermetallic compound could take place even at $450^{\circ} \mathrm{C}$, far below the $\mathrm{Fe}$ - $\mathrm{Al}$ eutectic temperature $\left(640^{\circ} \mathrm{C}\right)$, due to metastable interfaces that are produced by intensive deformation of deposited particles during CS. ${ }^{232}$ They also reported the phase transformations in nanostructured $\mathrm{Fe}-\mathrm{Al}^{143}$ and $\mathrm{Fe}(\mathrm{Al})-\mathrm{Al}_{2} \mathrm{O}_{3}$ coatings ${ }^{12}$. The metastable nanostructured $\mathrm{Fe}(\mathrm{Al})$ solid solution is retained in the coating without phase transformation. However, apart from FeAl, there is no trace of other intermetallics formed during PSHT. An annealing temperature of around $600^{\circ} \mathrm{C}$ is adequate to complete the intermetallic transformation, and strong interface diffusion can take place when the temperature reaches $950^{\circ} \mathrm{C}$ because of the melting, which further improves the adhesive strength of the coating. ${ }^{12} \mathrm{Jan}$ et al. ${ }^{233}$ reported similar intermetallic phase change as Wang et al. ${ }^{97}$, and they found that coating porosity increased with PSHT temperature, and these pores can be filled with molten metal to form a metallic-intermetallic composite.

(4) Therefore, the fabrication of metal-intermetallics composites through the CS + PSHT method should be carefully operated at a temperature range where expected intermetallics could form and it has less Kirkendall effect.

Besides, researchers have also identified intermetallics in the heat-treated $\mathrm{Al}-\mathrm{Cu},{ }^{51} \mathrm{Ni}-\mathrm{Ti},{ }^{224} \mathrm{Ni}-\mathrm{Sn},{ }^{234} \mathrm{Al}-\mathrm{Sn},{ }^{235}$

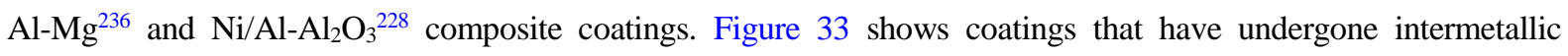
formation after heat-treatment, with a reaction layer, and even multi-layers, at the interface of the components. It should be noted that an intermetallic phase transformation also takes place at the interface between the coating and the substrate as indicated in Figs. 33. Therefore, by controlling the annealing time and temperature, one may get pure intermetallic coatings provided the possible useful melting of one metal.

\subsubsection{Directly cold-sprayed metal-intermetallic composites}

There are a very limited number of studies on directly cold-sprayed metal-intermetallic blend powders. With this method, one can clearly know the obtained intermetallic, while with the CS+PSHT method one can not 
absolutely ensure the expected intermetallics.

Cinca et al. ${ }^{223}$ deposited Fe40Al intermetalics onto 304 stainless steel and Ti substrates. It was found that coating thickness decreases with the increase of spraying distance. Dense coatings were obtained on stainless steel while coatings on Ti substrate contained cracks, which may be due to the larger difference in the thermal expansion coefficients between the Ti substrate and iron aluminide. Chandanayaka et al. ${ }^{237,238}$ sprayed $\mathrm{Ni}^{-\mathrm{Ni}} \mathrm{Al}_{3}$ blends with two kinds of $\mathrm{Ni}_{3} \mathrm{Al}$ sizes. The smaller sized $\mathrm{Ni}_{3} \mathrm{Al}$ results in a stronger interlocking and the slightly increased mechanical properties due to its higher particle velocity than coarse one. Bu et al. ${ }^{180}$ reported that the $\mathrm{Al}-\mathrm{Mg}_{17} \mathrm{Al}_{12}$ composite coating has a comparable anti-corrosion performance to pure $\mathrm{Al}$ bulk material, and the corrosion current density is reduced by more than one order of magnitude for the Mg substrate. Cherigui et al. ${ }^{239}$ found that the CS FeSiBNbCu-Al coatings have a soft magnetic character $(\mathrm{Hc}<1000 \mathrm{~A} / \mathrm{m})$, and the $\mathrm{FeSiBNbCu}-25$ wt.\% Al powder mixture is ideal to produce a homogenous coating with suitable magnetic properties. Steenkiste et al. ${ }^{240}$ applied CS to deposit composite coatings of Terfenol-D (( $\left.\left.\mathrm{Tb}_{0.3} \mathrm{Dy}_{0.7}\right) \mathrm{Fe}_{1.9}\right)$ and $\mathrm{SmFe}_{2}$ in a ductile matrix of $\mathrm{Al}, \mathrm{Cu}, \mathrm{Fe}$ or Mo to avoid constituent reaction. An induced magnetic coercivity was measured for the composite coatings with $\mathrm{Mo}$ and $\mathrm{Fe}$, and the addition of Mo yielded the largest value $(\mathrm{Hci}=3.7 \mathrm{kOe})$.

However, in this method the bonding between metal matrix and intermetallic seems not good as that formed with the CS+PSHT, which possibly limits its applications.

\section{Nanostructured coatings}

It is well known that nano-materials have many advantages over conventional materials such as high mechanical strength, excellent thermal and electrical properties, and superior optical and magnetic performance. But it is difficult to produce bulk nano-materials, and especially nano metallic materials, to use as structural materials. As mentioned above, CS shows great potential in fabricating nanostructured coatings or bulk components due to its low processing temperature, which enables the deposition of nanostructured materials without noticeable oxidation or grain growth.

\subsection{Nanostructured metallic coatings}

The research on this kind of coatings is mainly focused on $\mathrm{Al}$ or $\mathrm{Al}$ alloys, and the powder preparation method is ball milling (mostly cryomilling) or agglomerating commercial nano-powders to form micro-powders. A nanostructured Al coating was firstly reported by Mondoux et al. ${ }^{241}$ in 2004 . Using conventional and agglomerated nanostructured powders as feedstocks to deposit coatings, it was found that the microstructure of the powder was retained in the coating with hardness twice that of conventional coatings, which is attributed to 
the smaller grain size (Hall-Petch effect). Following that, nanocrystalline $\mathrm{Cu}^{242}$ and $\mathrm{Ni}^{243}$ coatings by $\mathrm{CS}$ cryomilled powders were successfully produced as shown in Figure 34. The nanocrystalline coatings generally present a dense, crack-free microstructure, and have a higher hardness than coarse-grained coatings. The low porosity, absence of cracks, indistinguishable particle interfaces, and absence of spallation and delamination indicated that the CS nanostructured coatings may demonstrate good cohesion and adhesion. ${ }^{244}$ Ajdelsztajn et al. ${ }^{144}$ cryomilled Al5083 powder and acquired particles with nano grain size $(20-30 \mathrm{~nm})$. The deposited coating had a grain size distribution of the same order of magnitude as the cryomilled Al5083 powder, while its hardness $\left(261 \pm 8 \mathrm{HV}_{0.3}\right)$ was higher than any other values reported for Al5083 consolidated with other techniques. Rokni et al. ${ }^{245}$ used the high-energy milled nanocrystalline Al5083 alloy powder (grain size: $40-50 \mathrm{~nm}$ ) as feedstock, and found that the resultant coating retained the nanocrystalline structure of the powder in the range of 50-100 nm. Elongated grains were also observed due to high velocity impact as shown in Figure 34b. Ajdelsztajn et al. ${ }^{144}$ also found elongated grains in the coatings deposited by cryomilled Al5083 powders, which proves that the deposition of nanocrystalline metallic particles are still based on their plastic deformation.

In contrast, Ghelichi et al. ${ }^{146}$ deposited both micro and nanocrystalline Al7075 powders on Al5052 substrate, and found that the cryomilled powder yields a porous coating structure, while the coating with a micron-sized powder shows almost no pores as shown in Figure 35. This is possibly due to the poor deformability of the prepared nano-sized powder and the unsuitable process parameters that were drawn from micro-particles experiments. A similar phenomenon was also observed for CS cryomilled Al2618. ${ }^{246}$

It should be pointed out that although the nanostructures of feedstocks are totally retained in the resultant coatings and the hardness is greatly increased, the cohesion of the nanostructured coatings is still not clear because of less data on it.

\subsection{Nanostructured metal-metal composite coatings}

In addition to elemental powders, nanostructured metal-metal composite coatings are also studied. Bacciochini et al. ${ }^{247}$ produced gasless reactive energetic materials with CS high-energy ball-milled Ni-Al powder (atom ratio of 1:1). The coating showed a dense microstructure with a porosity of about $1 \%$. Pitchuka et al. ${ }^{18}$ studied the dry sliding wear behavior of $\mathrm{Al}$ amorphous/nanocrystalline alloy powder (Al-4.4Y-4.3Ni-0.9Co-0.35Sc (at.\%)). It was found that the as-sprayed coatings exhibit higher steady state coefficient of friction (COF) of 0.55 compared to that of 0.38 for heat-treated coatings. Wear volume loss in the as-sprayed condition is $68 \%$ higher than that of heat-treated coatings, which is attributed to the micro-abrasion and delamination of the weak splats. However, micro-scratch tests showed that the as-sprayed coatings have a 
lower COF than that of heat-treated coatings, because these have a denser microstructure with embedded intermetallic phases, which results in higher scratch wear resistance. The scratch induced deformation mechanism changes from the shear-band dominated brittle mode in the as-sprayed coatings to the plowing type in the heat-treated coatings. Zhang et al. ${ }^{147}$ applied a mixture of $30 \mathrm{wt} . \%$ as-atomized and $70 \mathrm{wt} . \%$ as-cryomilled A12009 powders as feedstock to produce a coating without obvious pores and denser than that produced with pure nanocrystalline powder as shown in Figure 36. The extensively deformed as-atomized particles act as a binder in the coating to link the nanocrystalline particles, tamp the cracks and fill in pores between layers and particles, forming a dense coating. ${ }^{147}$ This is similar to the co-deposition mechanism of the metal-hard phase composite coatings described above.

Besides nanostructured $\mathrm{Al}$ or $\mathrm{Al}$ alloy based composite coatings, researchers have also investigated other nanostructured coatings with $\mathrm{CS}$. Li et al. ${ }^{142}$ ball-milled Fe and Si powders to produce nanocrystallites. As shown in Figure 37a, the grain size of the feedstock decreases with milling time and there is no grain growth during the CS process. Observations under TEM showed that the grains had a size of several tens of nanometers (Figure 37b). It should be noted that although grain size slightly decreases with increasing milling time, the coating hardness is little affected, ${ }^{142}$ possibly because the hardness of the milled powders has been saturated during ball-milling, so no further significant increase will yield for coatings. Wang et al. ${ }^{143}$ deposited ball-milled nanostructured Fe-Al alloy powder on stainless steel substrate. The metastable $\mathrm{Fe}(\mathrm{Al})$ alloy powders exhibit a lamellar structure (Figure 38a) and the lamellae are continuously refined with increasing ball-milling time. XRD results and TEM micrographs indicated that the phase structure of the as-sprayed coating was just a Fe-based solid solution, which transformed into the $\mathrm{FeAl}$ intermetallic phase during heat-treatment at $500^{\circ} \mathrm{C}$ for $25 \mathrm{~h}$, similar to that indicated in Figure 31. The grain size was in the range of 10-50 nm (Figure 38b), thus nanostructured $\mathrm{FeAl}$ intermetallic compound coatings were achieved. Kumar et al. ${ }^{249}$ deposited a $250 \mu \mathrm{m}$ thick nano Ni-20Cr coating on SA 516 boil steel with the ball-milled feedstock. High temperature oxidation tests at $900^{\circ} \mathrm{C}$ for 50 cycles showed that the coating reduced the weight gain of the base metal by $94 \%$ because $\mathrm{Ni}$ and $\mathrm{Cr}$ react preferentially with oxygen, forming $\mathrm{NiO}$ and $\mathrm{Cr}_{2} \mathrm{O}_{3}$, respectively. Compared with micro-sized CS $\mathrm{Ni}-20 \mathrm{Cr}$ coating, the weight gain of specimen is reduced by $64 \%$, and by $71 \%$ when the substrate was SA213-T22 steel, ${ }^{250}$ proving the high oxidation resistance of the nano Ni-20Cr coating.

In summary, by ball-milling of metal ingredients, nanostructured metal-metal composite coatings could be obtained with fine or metastable structures. The resultant coatings have higher hardness, but with a questionable cohesion, though some other properties are also superior. 


\subsection{Nanostructured metal-ceramic composite coatings}

Similar to common metal-ceramic composites, CS also showed potential in the fabrication of nanostructured metal-ceramic coatings. One typical example is nanostructured WC-Co coatings. Though the CS of micro-sized WC-Co coatings showed poor deposition efficiency than that by HVOF, ${ }^{244}$ the use of nanostructured feedstock significantly improves the deposition efficiency and density of CS coatings. This is possibly because the critical velocity is lowered and there is a higher surface area for contact between the binder phase and hard ceramic particles for effective deposition of nanostructured particles. Researchers ${ }^{21,154,155,158,169,251}$ found that a dense WC-Co coating can be deposited with CS without phase transformation or decarburization, with the nanostructures retained in the deposits. Shukla et al. ${ }^{20}$ initially reported on a nanostructured WC-10Co coating without decarburization in 2000. Later in 2002, Lima et al. ${ }^{21}$ prepared nanostructured WC-12Co coatings with agglomerated and sintered particles as shown in Figure 39. Though the coating thickness is only $10 \mu \mathrm{m}$, it shows a dense microstructure without pores, cracks or phase transformation. Li et al. ${ }^{158}$ and Kim et al. ${ }^{154,155}$ produced high quality nanostructured WC-Co coatings with low porosity and hardness comparable to the bulk. Li et al. ${ }^{158}$ also found that heat-treatment has little effect on coating hardness but can improve the coating bonding strength. Besides, Li et al. ${ }^{158}$ observed a broader WC peak in the XRD pattern of coating compared to the original powder, due to the grain refinement caused by high velocity impacts as shown in Figure 40. A similar phenomenon was also found in nanostructured WC-17Co coating. ${ }^{169}$

Figure 41 compares cermet coatings deposited with agglomerated nanostructured WC-12Co feedstocks of various porosities. ${ }^{169}$ From the obvious change of coating thickness, it is interestingly found that deposition efficiency increases with particle porosity. This is possibly because the non-uniform deformation leads to the increased density at the lower part (impact zone) of the particle while retaining the porous structure at the upper part (far away from the impact zone) (Figure 41h). The particle retains the pseudo-deformability when the following particles impact on it, permitting thick nanocrystalline WC-12Co coatings to be fabricated. Research by Lioma et al. ${ }^{252}$ WC-12Co-xNi also indicated that the porous structure favors particle deposition. However, Yandouzi et al. ${ }^{156}$ deposited both nano-sized and microcrystalline WC-Co coatings, and the nanostructured coating showed higher porosity and the lower hardness due to lack of plastic deformation, as in nanocrystalline Al coatings. ${ }^{246}$ These results mean that tailoring particle porosity seems a possible approach to acquire dense WC-Co coating with high deposition efficiency.

As reported by Yang et al. ${ }^{168}$, the coating toughness decreases with the increase of coating hardness. It is therefore a serious challenge to achieve strengthening and toughening at the same time. In order to overcome 
this problem, possible solutions include alloy phase toughening through plastic deformation, deviating the cracking path by reinforcement particles and increasing the interface bonding strength between the matrix phase and the ceramic particle. Yang et al. ${ }^{168,253}$ designed a bi-modal WC-12Co powder that possesses both high hardness and high toughness, as indicated by the square symbol in Figure 42a. The reinforcement phase is both micro-WC and nano-WC particles dispersed in the Co binder phase (Figure 14b). Fracture toughness can reach up to $18.9 \pm 4.0 \mathrm{MPa} \cdot \mathrm{m}^{1 / 2}$ after annealing at $1000^{\circ} \mathrm{C}$ for $6 \mathrm{~h}$ in a hydrogen atmosphere, which is comparable to the conventional WC-12Co bulk. This is due to the larger area of the bi-modal-sized fracture surface and the crack bridging caused by the micro-sized strengthening WC particles as indicated in Figure 42b. Crack bridging increases fracture toughness as it increases the fracture surface area and the energy consumption during cracking. The zigzag feature is encountered at both the micro WC particles and the nano WC particles, producing high fracture toughness. Meanwhile, the bi-modal WC-Co possesses a hardness as high as $1683 \pm 176 \mathrm{HV}$, which is similar to nano WC-12Co having a mean free path of the Co binder phase of $36 \mathrm{~nm}$. PSHT further increases the coating toughness and doubles the wear resistance of the CS WC-(Nano WC-Co) coating. ${ }^{253}$

It should be pointed out that although the grain size dose not get into nano-scale, the coating properties could be improved by powder design. Luo et al. [130] developed a core-shelled structured WC-Co powder as mentioned above (Figure 19), and the deposited coating is shown in Figure 43. The coating has a porosity of $0.7 \%$ and the hardness of this WC-10Co core is $1493 \pm 76.7 \mathrm{HV}_{0.1}$. The total WC content in the core-shell structured WC-Co coating was calculated to be $57.6 \mathrm{vol} . \%$. After annealing at $900^{\circ} \mathrm{C}$ for $2 \mathrm{~h}$, fracture toughness was increased by $70.6 \%$ (from $21.2 \pm 3.8 \mathrm{MPa} \mathrm{m}^{1 / 2}$ to $35.7 \pm 5.2 \mathrm{MPa} \mathrm{m}^{1 / 2}$ ) due to the improved deformability of the Co-rich WC-Co binder matrix as well as the enhanced bonding between WC-10Co cores and Co-rich WC-Co binder, where cracks were only observed in the WC-10Co cores of relatively low deformability.

Another interesting reinforcement can be obtained by carbon nanotubes (CNTs). The CNTs possess excellent strength, elastic modulus and stiffness, high thermal and electric conductivity while having low thermal expansion. All these make them a promising candidate for reinforcements to synthesize light weight, high strength structural MMCs. ${ }^{100,254}$ Low process temperature can avoid the unwanted reaction between the metal and CNTs. ${ }^{255}$ CNTs distribute homogeneously in the CS coatings ${ }^{100,254,255}$ as indicated in Figure 44a. The porosities of Al-0.5 wt.\% CNTs and Al-1 wt.\% CNTs coatings are (1.6 \pm 0.5$) \%$ and $(2.3 \pm 0.9) \%$, respectively. Nanoindentation of the composite yields a range of elastic modulus values between 40 and $120 \mathrm{GPa}$, whereas some regions had elastic modulus as high as $229 \mathrm{GPa}$ for Al-0.5 wt.\% CNTs, and $191 \mathrm{GPa}$ for Al-1 wt.\% CNTs coating. This is attributed to the reinforcement effect of CNTs and the local concentration of CNTs. ${ }^{149}$ Chen et 
al. ${ }^{254}$ reported that the CNTs retain their graphitic structure in Al-CNTs coatings as shown in Figure 44b, and nano scratch measurements showed that the addition of CNTs into Al matrix contributes to the increase in elastic modulus, hardness, yield strength, shear strength and nano scale wear resistance. The wear resistance is increased by $40 \%$ with the addition of $1.0 \mathrm{wt} . \% \mathrm{CNTs}$, while the COF remains unchanged. The higher hardness can be attributed to the fact that the MWCNTs inhibit plastic deformation that results in dislocation accumulation and intersection. ${ }^{255}$

For the $\mathrm{CS} \mathrm{Cu}-\mathrm{CNTs}$ coating, ${ }^{100}$ the $\mathrm{CNTs}$ dispersed uniformly in the $\mathrm{Cu}$ matrix, maintaining their tube structure as shown in Figure 44c. The composite coating had a higher thermal diffusivity than pure Cu coating, due to the dispersion of MWCNTs within the clean and closed CNT/Cu interfaces, which is the effect of high compressive stress during CS. ${ }^{100}$ Pialago et al. ${ }^{256}$ deposited Cu-CNTs composite coating with CNTs contents of up to 15 vol.\%. It was found that the particle size and deposition efficiency decreased with increasing CNTs content. The inner coating showed a lamellar structure while the surface layer showed a rough morphology containing 1.0-2.5 vol.\% micropores as shown in Figure 44d. They ${ }^{256,257}$ applied the Cu-CNTs composite coatings for boiling heat transfer, and found that the coating decreased the superheat and increased the maximum heat transfer coefficient by 1.21-1.74 times than that of the plain $\mathrm{Cu}$ plate. Besides, the addition of ceramics ( $\mathrm{SiC}, \mathrm{AlN}$, and $\mathrm{BN})$ in $\mathrm{Cu}-\mathrm{CNTs}$ further increases boiling heat transfer, and a combination of (5 vol.\% $\mathrm{CNT}+95$ vol. $\% \mathrm{Cu})+20$ vol. $\%$ AlN yields the highest enhancement ratio of 2.57. ${ }^{258}$

In literature there are certain works on other metal-ceramic nanostructured composite coatings. Cavaliere et al. ${ }^{259}$ found that addition of ceramics $\left(\mathrm{Al}_{2} \mathrm{O}_{3}, \mathrm{SiC}, \mathrm{BN}\right)$ into metal matrix $(\mathrm{Al}, \mathrm{Ni}, \mathrm{Cu})$ has strong effect on grain refinement, coating porosity and adhesion strength as shown in Figure 45. The presence of reinforcement phase affects the adiabatic shear instability governed recrystallization, as well as local plastic deformation, which accounts for the decrease in grain size and coating porosity. However, coating adhesion is decreased with increasing ceramics. ${ }^{259}$ Poirier et al. ${ }^{136}$ added 5 vol.\% nano-sized $\mathrm{Al}_{2} \mathrm{O}_{3}$ in an $\mathrm{Al}$ matrix, which lowers the powder and coating nano-hardness because the poor milling parameters were selected, leading to cracked particles with insufficient $\mathrm{Al}_{2} \mathrm{O}_{3}$ embedding in $\mathrm{Al}$. Hodder et al. [140] deposited commercially pure $\mathrm{Al}$ mixed with either $10 \mu \mathrm{m}$ or agglomerated $20 \mathrm{~nm} \mathrm{Al} \mathrm{O}_{3}$ in weight fractions of 25 to $95 \mathrm{wt} . \%$, with the highest ceramic contents in the coating being 48 wt. $\%$ and 38 wt. $\%$, respectively. However, the maximum microhardness of the latter was higher than that of the former due to the increased spreading of the nano particles in the coating, which increases load-bearing capability of the reinforcement particles. Yandouzi et al. ${ }^{260}$ fabricated the nanocrystalline $\mathrm{Al} 3556-20$ wt.\% $\mathrm{B}_{4} \mathrm{C}$ coating with pulsed cold spraying (PCS), and the coating showed a low 
porosity with $\mathrm{B}_{4} \mathrm{C}$ uniformly distributed in the nanostructured Al5356 matrix, which greatly improves the coating dry sliding wear resistance. Nanostructured $\mathrm{Fe}-\mathrm{Cu}-\mathrm{Al}-\mathrm{Al}_{2} \mathrm{O}_{3}$ exhibited lower $\mathrm{COF}$ and wear rate than their constituting elements and/or to benchmark materials due to the appropriate balance of soft and hard phases, and to the nanostructuring of the matrix. High amounts of grain boundries hinders the formatiuon and motion of dislocations, thus, the deformation of nanostructured materials is restrained. ${ }^{261}$ Luo et al. ${ }^{14}$ fabricated a cubic BN particle-reinforced NiCrAl nano-composite coating by CS. A Ni-based amorphous layer with a thickness ranging from 3 to $8 \mathrm{~nm}$ was located at the cBN/NiCrAl interface and was surrounded with crystalline Ni-based alloy. These Ni-based alloy crystals exhibited a preferred orientation with the $\{111\}$ plane frequently parallel to the interfaces of $\mathrm{cBN} / \mathrm{NiCrAl}$ as shown in Figure 46. They also reported that the as-sprayed 20 vol. $\%$ cBN/NiCrAl nano-composite coating yields a hardness of $1063 \mathrm{HV}_{0.3}$. Both hardness and wear resistance are comparable to that of the high velocity oxygen fuel (HVOF)-sprayed WC-12Co coating. After heat-treated at $750^{\circ} \mathrm{C}$ for $5 \mathrm{~h}$, the coating wear resistance is increased by $33 \%$ due to the enhanced particle bonding. ${ }^{13}$

In addition, Phani et al. ${ }^{153}$ studied the effect of high temperature heat-treatment on porosity, thermal conductivity and grain size of $\mathrm{Cu}-\mathrm{Al}_{2} \mathrm{O}_{3}$ nano-composite coating. It was found that heat-treatment has little effect on porosity. In the meantime, conductivity rises a little with the increase of temperature. The grain growth was restrained due to the presence of $\mathrm{Al}_{2} \mathrm{O}_{3}$ even when heat-treated at $950^{\circ} \mathrm{C}$, which is close to the melting point of copper owing to the presence of fine $\mathrm{Al}_{2} \mathrm{O}_{3}$.

In summary, the nanostructured metal-ceramic coatings are one of the most promising composites because of their excellent properties. The careful tailoring of powder and processing parameters will make these kinds of coatings very attractive in applications. However, again, the cohesion, ductility and toughness of the composite are the crux. PSHT can help improve them with the retaining of their nanostructures.

\subsection{Nanostructured ceramic coatings}

It is interesting that CS can also be used to deposit nanocrystalline ceramic coatings, although initially it appears impossible as CS requires plastic deformation to work. The key requirement for deposition is a vacuum chamber and a specially designed nozzle, and it is therefore named as vacuum cold spraying (VCS). It was initially developed by Akedo and his coworkers ${ }^{263}$ and initially termed as aerosol deposition (AD), in which nano-particles are sprayed in a vacuum chamber using a propellant gas flow of helium or air. Although the velocity reached is lower than that of usual CS, this process reduces significantly the bow shock effect, making it possible to deposit very small particles. It has been used to fabricate lead-zirconate-titanate (PZT), $\alpha-\mathrm{Al}_{2} \mathrm{O}_{3}$, $\mathrm{Y}_{2} \mathrm{O}_{3}$, YSZ, AlN, $\mathrm{MgB}_{2}$, and other nanocrystalline ceramic films of high transparency, high hardness, and 
high-breakdown voltage at room temperature. ${ }^{62,262,263}$ Hanft et al. detailedly summarized the materials that could be deposited by AD and applications. ${ }^{264}$

As indicated in Figure 47, dense $\alpha-\mathrm{Al}_{2} \mathrm{O}_{3}$ coating with a thickness of about $3 \mu \mathrm{m}$ was deposited on a $\mathrm{SiO}_{2}$ substrate. XRD results confirmed that there is no phase transformation during deposition. The broadening of the spectral peaks indicates the reduction of grain size. Figure 47c indicated randomly oriented polycrystalline nanostructure with crystal grains smaller than $20 \mathrm{~nm}$ in length. It is worth pointing out that the ceramic particles seem to have experienced some extent of plastic deformation. ${ }^{263,265}$ The fracture and the multiple impacts of fine particles during deposition induce the generation of active surfaces of particles, allowing the bonding of particles and forming a dense ceramic layer. ${ }^{62}$ Cao et al. ${ }^{266,267}$ identified that lattice collapse and damage, internal dislocation, brittle fracture, and inelastic crack nucleation near dislocations are the main factors responsible for particle deformation at high impact velocities. Thus, as Park et al. ${ }^{268}$ elaborated, plasticization and fragmentation are the main deposition mechanisms of VCS.

Because of the very low process temperature and the ability to deposit thin ceramic films on various substrates, even curved surfaces, VCS has been applied in the fabrication of electro-ceramic for piezoelectric devices and electro-optic materials for optical devices. In the case of PZT, for example, in order to eliminate structure defects and the reduction of the crystallite size during deposition, PSHT is necessary to improve the ferroelectric properties. As shown in Figure 48, the PSHT temperature for the coating deposited by AD is lower compared with traditional methods. After annealing at $600^{\circ} \mathrm{C}$, the dielectric constant and the piezoelectric constant of layers were comparable to the values of conventional thin-film formation methods. ${ }^{263}$

Following Akedo et al., researchers have investigated other nanostructured ceramic coatings by VCS, such as $\mathrm{HA},{ }^{106} \mathrm{TiO}_{2},{ }^{269-272} \mathrm{TiN}^{273,274}$. The photocatalytic efficiency of $\mathrm{CS}$ nanostructured anatase $\left(\mathrm{TiO}_{2}\right)$ coating is comparable to the one obtained by competitive technologies like dip-coating P25 $5^{\circledR}$ photocatalysts. ${ }^{103}$ The solar cells assembled by VCS nanocrystalline $\mathrm{TiO}_{2}$ powders yielded a short-circuit current density of $7.3 \mathrm{~mA} / \mathrm{cm}^{2}$ and an energy conversion efficiency of $2.4 \%$, which are comparable to those by other methods such as mechanical compression and hydrothermal crystallization. ${ }^{269,270}$ After post-sintering at $450^{\circ} \mathrm{C}$ for 30 mins, these values increased to $14.0 \mathrm{~mA} / \mathrm{cm}^{2}$ and $4.9 \%$, respectively, due to the improvement of intimate contacts between nano- $\mathrm{TiO}_{2}$ particles in the coating. In addition, applying nano- $\mathrm{TiO}_{2}$ as a blocking layer on fluorine-doped tin oxide glass can increase the open-circuit voltage and short-circuit current density due to the blocking of electron leakage from the fluorine-doped tin oxide surface to the electrolyte, hence, the photon-to-current conversion efficiency was increased from 3.3\% to 5.6\%.${ }^{275}$ Moreover, Yang et al. ${ }^{271}$ found that the short-circuit photocurrent 
density of the cell increases with accelerating gas flow due to the improved coating compactness. The VCS TiN coating exhibits a low hardness of $279-490 \mathrm{HV}$ with a porosity ranging from 58.3 to $67.6 \%$ and the pore size mainly ranging from 2 to $8 \mathrm{~nm}$, which results in a relatively good fracture toughness of about $3.12 \mathrm{MPa} \cdot \mathrm{m}^{1 / 2}$. It was also found that the sheet resistance and electrical resistivity of the TiN coatings decrease in a dramatic way with increasing coating thickness because of the higher tamping effect, which results in fewer defects, and in turn decreases the electron transfer resistance. The minimum sheet resistance $(127 \Omega)$ is lower than that of the TiN film deposited by CVD $(186.7 \Omega)$, and a minimum electrical resistivity of $3 \times 10^{-3} \Omega \cdot \mathrm{m}$ is achieved. ${ }^{273,274}$

\subsection{Nanostructured ceramic composite coatings}

A few researchers have also investigated nanostructured ceramic composite coatings by VCS, such as hydroxyapatite (HA)-graphene nanosheet $(\mathrm{GN}),{ }^{105,106} \mathrm{SiC}^{-\mathrm{TiN}^{276}}$ and graphene- $\mathrm{TiO}_{2}{ }^{277}$ composite coatings. Cross sections of the nanostructured ceramic composite coatings are shown in Figure 49. The coatings also present a relatively dense structure with the presence of micro-cracks and micropores. Liu et al. ${ }^{105,106}$ found that nanocrystalline GN homogeneously embedded in the HA matrix and certain nano HA particles experienced plastic deformation (Figure 62b), which is similar to the phenomenon reported by Akedo et al. ${ }^{263}$ and Cao et al. ${ }^{266,267}$. The HA-GN composite coating markedly enhanced the attachment and proliferation of the osteoblast cells, which has great potential in bio-application. ${ }^{105}$

Kim et al. ${ }^{277}$ found that the optimal concentration of $0.3 \mathrm{wt} . \%$ graphene in $\mathrm{TiO}_{2}$ feedstock increased the energy conversion efficiency from $3.14 \%$ of pure $\mathrm{TiO}_{2}$ to $5.02 \%$. Further, the electrical resistivity of nanocrystalline SiC-TiN composite coating decreases with increasing TiN content, from the order of $10^{14} \Omega \cdot \mathrm{m}$ of the undoped-SiC to the minimum $1.82 \Omega \cdot \mathrm{m}$ with $50 \mathrm{~mol} \% \mathrm{TiN}$ in the coating, ${ }^{276}$ which is contributed to the electron-transporting of the conductive TiN phase.

By forming a composite film, properties can be adjusted, for instance, electrical parameters like conductivity or permittivity, as well as mechanical characteristics like hardness, porosity, or adhesion to the substrate. Depending on the mixing ratio and relative particle sizes of the powders, one can obtain either a dispersion of one phase in a continuous matrix of the other, or two interpenetrating continuous phases. ${ }^{264,278}$

\section{Potential applications of composite or nanostructured coatings}

Based on the above results, CS is expected to be applied to most fields where thermal spraying has been already used because CS can produce metallic or composite coatings with properties superior or comparable to thermal sprayed ones. Its applications can be summarized as follows.

\subsection{Protective coatings}


The basic use of CS is to fabricate coatings providing resistance to corrosion environment, elevated temperatures and wear.

(1) Corrosion resistant coatings. It is well known that TS coatings with post-sealing treatment seem to provide good protection for the substrates by dual functions, i.e. physical isolation and electrochemical protection acting as a sacrificial anode to the substrate. However, the excessive heat input to the substrates may lead to distortion and more residual stresses. Therefore, CS emerges as a better choice to protect the substrate. For components which work in corrosive environments such as sea water or acid atmosphere, anti-corrosion coatings are necessary. CS can be used to fabricate anti-corrosion coatings, such as $\mathrm{Zn}, \mathrm{Al}, \mathrm{Ni}$ and their alloys based composite coatings such as $\mathrm{Al}_{-} \mathrm{Al}_{2} \mathrm{O}_{3}, \mathrm{Ni}-\mathrm{Al}_{2} \mathrm{O}_{3}, \mathrm{Al}-\mathrm{Zn}$ and $\mathrm{Al}-\mathrm{Si}-\mathrm{Zn},{ }^{88,90,91}$ without the oxidation of the metallic powders. $\mathrm{Cu}$-Al-bronze composite coatings can enhance the corrosion and cavitation resistance of ship propellers in marine environments. ${ }^{279}$ In contrast to the relatively porous and oxidized thermal sprayed protective coatings, such as $\mathrm{Zn}, \mathrm{Al}$ and their alloys, CS coatings have higher resistance to corrosive media and longer service life. The key problem for these CS protective coatings is to develop industrial equipment and techniques to economically and easily deposit coatings on large and complex surfaces. ${ }^{280}(2)$

High-temperature oxidation resistant coatings. This kind of coatings is widely used in high-temperature parts, such as aero engines, turbines and boilers. For examples, Ni-Cr oxidation resistant coatings for boilers, ${ }^{99}$ $\mathrm{Cu}-\mathrm{Cr}-\mathrm{Nb}$ deposits $^{281}$ for high thermal and electrical conductivities at elevated temperatures in rocket engines, intermetallics including $\mathrm{Al}-\mathrm{Ni},{ }^{98} \mathrm{Fe}-\mathrm{Al},{ }^{97}$ nanostructured $\mathrm{NiCrAlY}$ alloy ${ }^{282,283}$ and $\mathrm{CoNiCrAlY}{ }^{284,285}$ bond coat for thermal barrier coatings.

(3) Wear resistant coatings. To increase the wear resistance of industrial components, wear-resistant coatings can be deposited by CS, such as cermet coatings, ceramic reinforced MMC coatings and anti-friction alloy coatings (Al-Si alloy, ${ }^{90}$ bronzes, ${ }^{286}{\mathrm{WC}-\mathrm{Co}^{157}}^{157}$ and stellite coatings ${ }^{288,289}$ ). In addition, abradable sealing coatings are designed to preferentially abrade when contact is made with a mating part. A patent on CS nickel-graphite abradable coating has been granted, ${ }^{290}$ and it is promising to expand to coatings with other materials such as Al-12Si alloy, Al-bronze, Ni-Cr-Al alloys and their composites with polymer or graphite additions. $^{280}$

\subsection{Functional coatings}

CS has also been applied to non-traditional fields, e.g. energy, photovoltaic, electronics, medical, catalytic. ${ }^{291,292}$ One such is the fabrication of nanostructured functional coatings. For examples, $\mathrm{CS} \mathrm{TiO}_{2}$ films on glasses with mesoporous microstructure can be used in applications of photocatalytic degradation and 
dye-sensitized solar cells. ${ }^{269,270} \mathrm{TiO}_{2}$ and $\mathrm{TiO}_{2}$ - $\mathrm{Zn}$ coatings can also be used as catalytic coatings. ${ }^{102,103}$ Moreover, nanostructured $\mathrm{TiO}_{2}$ may also be used as bioactive coatings. ${ }^{109,293,294} \mathrm{Ag}-\mathrm{SnO}_{2}$ and $\mathrm{Ag}-\mathrm{Ni}$ coatings can be used as industrial electrical contacts for contactors and circuit breakers. ${ }^{101,104} \mathrm{Cu}$-CNTs composite coatings are used for boiling heat transfer. ${ }^{100,256-258} \mathrm{FeSiBNbCu}-\mathrm{Al}$ coatings are used as soft magnetic materials. ${ }^{239,240} \mathrm{HA}-\mathrm{GN}$ and HA-Ti composite coatings are deposited on titanium substrates as load-bearing implant materials for biomedical applications. ${ }^{105-107,212,295}$ Forthemore, cold sprayed coatings, particularly $\mathrm{Cu}$ or Ag coatings, have showed excellent electrical conductivity which is comparable to their bulk state. ${ }^{296-298}$ In some cases, CS may gradually replace expensive and not flexible techniques such as physical vapor deposition (PVD) and silver frit screen printing. ${ }^{299}$

\subsection{Near-net forming or additive manufacturing}

As a spray forming process similar to thermal spraying, CS can also be used to directly fabricate components because of its high deposition rate and ability to combine many dissimilar materials to produce a single component without obvious melting or oxidation of the feedstock, ${ }^{112}$ which is similar to near-net shape manufacturing technology. As such it is possible to construct components with freeform surfaces, internal channels and embedded devices. ${ }^{11}$ Recently, General Electric Co. (GE) reported that a new additive manufacturing technology, named Cold Spray 3D Printing, was developed aiming at building a part or adding material to repair an existing part. Although it is not new in the thermal spray community, it is a novel application of CS. CS components can be easily machined to a final shape. CS has been demonstrated to manufacture large parts, sputtering targets or large rotating targets (e.g. $\mathrm{Zn}-\mathrm{Al}$ and $\mathrm{Zn}-\mathrm{Sn}$ ), and fin arrays, ${ }^{190,300}$ as shown in Figure 50.

\subsection{Component repair}

When compared to forming a part, CS seems more suitable for the quick repair by spraying powders onto damaged parts, such as turbine blades, aircraft skin, helicopter mast support, gearbox, panel fastener hole, pistons, cylinders, valves rings, bearing components, sputtering targets and pump elements, ${ }^{305-307}$ and most of them can be fulfilled with composites. As a result, the life of a component is extended, and this is especially important for expensive parts. In addition, with portable CS equipment, on-site repairing can be attempted without having to remove damaged parts out of the machine. For examples, CS has been used to repair military hardware such as the engine block, ${ }^{308}$ the flight control module of the gear box ${ }^{309}$ Lots of patents on restoration with CS have been granted and it is also worth noting that the Air Force Research Laboratory of the US and the United Technologies are improving CS to repair major components of the UH-60 Black Hawk helicopters. ${ }^{310}$ 
Besides, CS can also be used to restore corroded areas of the Steyr engine with the $\mathrm{Cu}-\mathrm{Zn}^{-} \mathrm{Al}_{2} \mathrm{O}_{3}$ composite coating, ${ }^{311}$ and for repairs on corrosion sensitive materials such as magnesium and aluminum alloy components (Figure 51), ${ }^{9,299,312-314}$ worn surface of aluminum mold, ${ }^{315}$ degraded areas of titanium alloy turbine components and martensitic stainless steel components, ${ }^{305,315}$ in-situ repairing of the eroded bellows by using the $\mathrm{Ni} / \mathrm{Al}_{2} \mathrm{O}_{3}$ coating. ${ }^{91}$ Furthermore, it has been found that a CS patch can enhance the damage tolerance of structural components and restrain crack growth, thus showing great potential in restoring the airworthiness and functionality of aging aircraft structures. ${ }^{316}$ Therefore, CS composites can have a wide use in repair and improvement of metal structures.

\section{Summary and outlook}

Based on the literature review and above discussion, it is clear that CS is a promising technique to fabricate advanced metallic, composite and nanostructured coatings, as well as near-net-shape components and repairs. It is gradually moving out of lab research to industrial applications because of the deeper understanding of the process, the advancement of technology, and the upgrading of spray equipment. The following concluding remarks could be made.

\subsection{Importance of powder preparation}

Powder preparation prior to spraying takes an important role in deposition of composites. The methods currently applied mainly include mechanical blending, ball-milling, spray drying, agglomerating and sintering, coating or cladding. Each method has its advantages and disadvantages. Mechanical blending is an easy and simple way to mix the powders, and the resultant coatings show all-right properties but the distribution of hard phase is difficult to control. Ball-milling is proved to be a good way to prepare well-dispersed composite and nanostructured powders, and the obtained coatings usually have good properties, but the flowability of the milled powders is poor, even for cryomilling, not well suitable for spraying. A following powder treatment may be needed to help powder feeding. In addition, the podwers are ready to be polluted by the mill jar and balls, or by oxidation when exposed to air. Another good method is the coating or cladding process, which will yield a controllable volume fraction of hard phase. However, it is difficult to get a thick coated metal layer or small sizes of powders. As for spray drying or agglomerating and sintering, they are employed for some special materials, e.g. cermets. Spray drying can also be used to treat the milled fine powders. In order to increase the deposition efficiency of hard reinforcement particles and precisely control of its content and distribution in the deposits, as well as to prepare nanostructured powders, these methods should be carefully selected. With properly prepared feedstocks, one can produce coatings according to specification. The tendency is to design 
composite powders by a combination of methods to produce coatings with desired properties for complicated working conditions. The main problems to be solved are as follows.

(1) to find economic and efficient methods for micro- or nano-sized powder preparation.

(2) ball-milling parameters take important roles in the quality of prepared powders, how do they influence the coating quality?

\subsection{Co-deposition of composite powders}

The bonding mechanisms of the composite particles lie largely on the co-deposition mechanism of metal and hard phases besides the conventional metal-metal bonding mechanisms. The severely deformed soft metal phase acts as a binder, while the hard phase embedded in the matrix acts as reinforcement. Further to that, the hard particles have an "activation" effect on the substrate or previously deposited metals, cleaning oxide films on particles and/or substrate surfaces and increasing their activity for metallurgical bonding at the same time. Another factor may be the "tamping effect" of hard phase. However, the collision between ceramic particles will take the leadership when its content is relatively high, and its erosion effect will lower the deposition efficiency.

\subsection{Optimization of composite coatings}

CS is a relatively easy and cost-effective technique to deposit composite coatings with comparable or improved properties than as compared other methods. Presence of ceramic particles in feedstock enhances the coating by creation of a composite structure, densifies the coating, increases the coating adhesion, and improves the process stability. The tamping effect of hard phase contributes to the increase of coating compactness and adhesion. The addition of ceramics generally has no negative effect on coating corrosion behavior, but can greatly increase coating hardness, possibly lower COF and enhance coating wear resistance if the hard phase content is appropriate. However, when the content of hard phase is too high, the deposition efficiency will significantly decrease by its erosion effect, and thus the coating adhesion is degraded. Generally speaking, the content of hard phase in the coating increases with the increase of that in the feedstock until a maximum value, and then decreases. Consequently, the coating hardness also increases with the content of hard phase. While for coating adhesion, it presents a tendency similar to deposition efficiency as increasing the hard phase content. By controlling the composition of the original feedstock, it is possible to deposit coatings with specified properties. Preliminary studies have also shown that CS together with PSHT is a promising technique to fabricate metal-intermetallic coatings or even pure intermetallics coatings. Careful selection of heat treatment temperature (e.g. $500-580^{\circ} \mathrm{C}$ for $\mathrm{Ti} / \mathrm{Al}$ deposit) could avoid the obvious pores formed by the Kirkendall effect. There are still some important issues to be solved for CS composites. 
(1) the most important thing is how to optimize the size, concentration, and distribution of ceramic phase in metal-ceramic composite coatings to tailor composite properties;

(2) effect of process parameters as well as PSHT on composite coating microstructure and properties;

(3) how to control the degree of phase transformation in forming the intermetallics during PSHT to obtain the desired phase?

\subsection{Optimization of nanostructured coatings}

As for nanocrystalline materials, CS is also a promising coating technique for its low process temperature. The characteristics of nanocrystalline feedstock can be retained in the deposits, producing coatings with good properties such as high hardness, excellent wear resistance, high electrical and thermal conductivity, high dielectric constant and piezoelectric constant, which are difficult to acquire through other conventional methods. When spraying with nanostructured Al alloy powders, the coating usually presents a relatively high porosity compared to the micron-sized powders, possibly because the spray parameters are not well in the deposition window to make the particles deform extensively. As for WC-Co, the deposition efficiency of nano powders is higher than that of micron-sized powders, and a good toughness of nanostructured coating could be obtained by designing the feedstock powders. During annealing of the nano-particles reinforced composite coatings, the grain growth is restrained due to the presence of nano-ceramic-particles, for example, nano $\mathrm{Al}_{2} \mathrm{O}_{3}$ in the $\mathrm{Cu}-\mathrm{Al}_{2} \mathrm{O}_{3}$ coating will keep the small grain size even heat-treated at $950^{\circ} \mathrm{C}$. The current challenge to deposit nanocrystalline materials lies in the control of nanostructures in the coating via powder preparation and processing parameters. Some important issues to be solved are:

(1) as mentioned above, the preparation of appropriate powder is necessary.

(2) to optimize the process parameters including nozzle design for nanostructured coatings to ensure compact coating.

(3) how to ensure the deposition of thick, uniform and large-area coatings through process optimization.

(4) lack of data on the properties of nanostructured coatings, e.g. adhesion/cohesion.

\subsection{Expanding the applications}

In order to expand the applications of CS, some general aspects should also be considered.

(1) refer to thermal spraying, establishment of standards to quantitatively characterize the coatings microstructure and properties will be very helpful.

(2) the performance of coatings in service, e.g. corrosion, fatigue and wear, when exposed to industrial environments, is also an important aspect to be explored. 
(3) how to improve the toughness of as-sprayed coatings, which is important in order to use in spray forming

and restoration?

(4) develop high-performance portable CS equipment to extend range of open applications.

(5) develop laser assisted CS (or hybrid CS), where the necessary thermal energy is provide to soften the high strength materials, e.g. superalloys, intermetallics.

\section{Funding}

This work is supported by National Natural Science Foundation of China under Grant (51574196); the State Key Lab of Advanced Metals and Materials under Grant (2013-ZD07); the Fundamental Research Funds for the Central Universities under Grant (3102014JC02010404); the Research Fund of the State Key Laboratory of Solidification Processing under Grant (108-QP-2014, 122-QZ-2015) and the 111 Project under Grant (B08040). The authors would like to thank the graduates, Mr. Dongdong Zhang, Dr. Chunjie Huang, for their help in literature collection. The authors also appreciate the valuable comments from all the reviewers.

\section{References}

[1] V.K. Champagne, The cold spray materials deposition process: fundamentals and applications. (2007).

[2] S. Celotto, J. Pattison, J.S. Ho, A.N. Johnson, and W. O'Neill, 5-the economics of the cold spray process. Cold Spray Materials Deposition Process. (2007) pp. 72-101.

[3] H. Assadi, H. Kreye, F. Gärtner and T. Klassen, Cold spraying-a materials perspective, Acta Mater. 116, 382-407 (2016).

[4] A. Papyrin, Cold spray technology, Adv. Mater. Process, 159, 49-51, (2001).

[5] W.Y. Li, S. Yin and X.F. Wang, Numerical investigations of the effect of oblique impact on particle deformation in cold spraying by the SPH method, Appl. Surf. Sci. 256, 3725-3734 (2010).

[6] W.Y. Li, C. Zhang, C.J. Li and H.L. Liao, Modeling aspects of high velocity impact of particles in cold spraying by explicit finite element analysis, J. Therm. Spray Techn. 18, 921-933 (2009).

[7] S. Yin, X.F. Wang, B.P. Xu and W.Y. Li, Examination on the calculation method for modeling the multi-particle impact process in cold spraying, J. Therm. Spray Techn. 19, 1032-1041 (2010).

[8] H. Assadi, H. Kreye, F. Gärtner and T. Klassen, Cold spraying-A materials perspective, Acta Mater. 116, 382-407 (2016).

[9] V. Champagne and D. Helfritch, The unique abilities of cold spray deposition, Inter. Mater. Rev. 61, 437-55 (2016).

[10] A. Papyrin, The development of the cold spray process[M]// The Cold Spray Materials Deposition Process. (2007); pp. 11-42.

[11] M.F. Smith, Comparing cold spray with thermal spray coating technologies. The Cold Spray Materials Deposition Process. (2007).

[12] H.T. Wang, G.J. Yang and C.X. Li, Effect of heat treatment on the microstructure and property of cold-sprayed nanostructured $\mathrm{FeAl} / \mathrm{Al}_{2} \mathrm{O}_{3}$ intermetallic composite coating, Vacuum 83, 146-152 (2008).

[13] X.T. Luo, E.J. Yang, F.L. Shang, G.J. Yang, C.X. Li and C.J. Li, Microstructure, mechanical properties, and two-body abrasive wear behavior of cold-sprayed 20 vol.\% cubic BN-NiCrAl nanocomposite coating, $J$. Therm. Spray Techn. 23, 1181-1190 (2014).

[14] X.T. Luo., G.J. Yang, C.J. Li and K. Kondoh, High strain rate induced localized amorphization in cubic BN/NiCrAl nanocomposite through high velocity impact, Scripta Mater. 65, 581-584 (2011).

[15] S. Yoon, C. Lee, H. Choi and H. Jo, Kinetic spraying deposition behavior of bulk amorphous NiTiZrSiSn feedstock, Mater. Sci. Eng. A. 415, 45-52 (2006).

[16] H. Choi, S. Yoon, G. Kim, H. Jo and C. Lee, Phase evolutions of bulk amorphous NiTiZrSiSn feedstock during thermal and kinetic spraying processes, Scripta. Mater. 53, 125-130 (2005).

[17] A. List, F. Gärtner, T. Mori, M. Schulze, H. Assadi and S. Kuroda, Cold spraying of amorphous $\mathrm{Cu}_{50} \mathrm{Zr}_{50}$ alloys, J. Therm. Spray Techn. 24, 108-118 (2015). 
[18] S.B. Pitchuka, B. Boesl, C. Zhang, D. Lahiri, A. Nieto, G. Sundararajan, et al, Dry sliding wear behavior of cold sprayed aluminum amorphous/nanocrystalline alloy coatings, Surf. Coat. Techn. 238, 118-125 (2014).

[19] J. Henao, A. Concustell, I.G. Cano, N. Cinca, S. Dosta and J.M. Guilemany, Influence of cold gas spray process conditions on the microstructure of Fe-based amorphous coatings, J. Alloy. Compd. 622, 995-999 (2015).

[20] V. Shukla, G.S. Elliott and B.H. Kear, Nanopowder deposition by supersonic rectangular jet impingement, J. Therm. Spray Techn. 9, 394-398 (2000).

[21] R.S. Lima, J. Karthikeyan, C.M. Kay, J. Lindemann and C.C. Berndt, Microstructural characteristics of cold-sprayed nanostructured WC-Co coatings, Thin Solid Films 416, 129-135 (2002).

[22] M. Couto, S. Dosta, M. Torrell, J. Fernández and J.M. Guilemany, Cold spray deposition of WC-17 and 12Co cermets onto aluminum, Surf. Coat. Techn. 235, 54-61 (2013).

[23] W.Y. Li, C.J. Li and H. Liao, Effect of annealing treatment on the microstructure and properties of cold-sprayed Cu coating, J. Therm. Spray Techn. 15, 206-211 (2006).

[24] C. Borchers, F. Gärtner, T. Stoltenhoff, H. Assadi and H. Kreye, Microstructural and macroscopic properties of cold sprayed copper coatings, J. Appl. Phys. 93, 10064-10070 (2003).

[25] W.B. Choi, L. Li, V. Luzin, R. Neiser, T. Gnäupel-Herold, H.J. Prask, et al, Integrated characterization of cold sprayed aluminum coatings, Acta. Mater. 55, 857-866 (2007).

[26] Y. Tao, T. Xiong, C. Sun, L. Kong, X. Cui, T. Li, et al, Microstructure and corrosion performance of a cold sprayed aluminium coating on AZ91D magnesium alloy, Corros. Sci. 52, 3191-3197 (2010).

[27] H.R. Wang, W.Y. Li, L. Ma, J. Wang and Q. Wang, Corrosion behavior of cold sprayed titanium protective coating on 1Cr13 substrate in seawater, Surf. Coat. Techn. 201, 5203-5206 (2007).

[28] W. Wong, E. Irissou, A.N. Ryabinin, J.G. Legoux and S. Yue, Influence of helium and nitrogen gases on the properties of cold gas dynamic sprayed pure titanium coatings, J. Therm. Spray Techn. 20, 213-226 (2011).

[29] M. Gardon, A. Latorre, M. Torrell, S. Dosta, J. Fernández and J.M. Guilemany, Cold gas spray titanium coatings onto a biocompatible polymer, Mater. Lett. 106, 97-99 (2013).

[30] K. Binder, J. Gottschalk, M. Kollenda, F. Gärtner and T Klassen, Influence of impact angle and gas temperature on mechanical properties of titanium cold spray deposits, J. Therm. Spray Techn. 20, 234-242 (2011).

[31] T. Suhonen, T. Varis, S. Dosta, M. Torrell and J.M. Guilemany, Residual stress development in cold sprayed Al, Cu and Ti coatings, Acta Mater. 61, 6329-6337 (2013).

[32] L. Pawlowski, The science and engineering of thermal spray coatings, John Wiley \& Sons, (2008).

[33] S. Dosta, G. Bolelli, A. Candeli, L. Lusvarghi, I.G. Cano, J.M. Guilemany, Plastic deformation phenomena during cold spray impact of WC-Co particles onto metal substrates, Acta Mater. 124, 173-181 (2017).

[34] K. Spencer, V. Luzin, N. Matthews, M.X. Zhang, Residual stresses in cold spray Al coatings: the effect of alloying and of process parameters, Surf. Coat. Tech. 206, 4249-4255 (2012).

[35] S. Yin, X.F. Wang, X.K. Suo, H.L. Liao, Z.W. Guo, W.Y. Li, C. Coddet, Deposition behavior of thermally softened copper particles in cold spraying, Acta Mater. 61, 5105-5118 (2013).

[36] R.C. Dykhuizen, M.F. Smith, D.L. Gilmore, R.A. Neiser, X. Jiang and S. Sampath, Impact of high velocity cold spray particles, J. Therm. Spray Techn. 8, 559-564 (1999).

[37] T. Hussain, Cold spraying of Ti: a review of bonding mechanisms microstructure and properties, Key Eng. Mater. 533, 53-90 (2013).

[38] C. Borchers, T. Schmidt, F. Gärtner and H. Kreye, High strain rate deformation microstructures of stainless steel 316L by cold spraying and explosive powder compaction, Appl. Phys. A 90, 517-526 (2008).

[39] H. Assadi, F. Gärtner, T. Stoltenhoff and H. Kreye, Bonding mechanism in cold gas spraying, Acta Mater. 51, 4379-4394 (2003).

[40] W.Y. Li and W. Gao, Some aspects on 3D numerical modeling of high velocity impact of particles in cold spraying by explicit finite element analysis, Appl. Surf. Sci. 55, 7878-7892 (2009).

[41] T, Schmidt, F. Gaertner and H. Kreye, New developments in cold spray based on higher gas and particle temperatures, J. Therm. Spray Techn. 15, 488-494 (2006).

[42] M. Grujicic, J.R. Saylor, D.E. Beasley, W.S. DeRosset and D. Helfritch, Computational analysis of the interfacial bonding between feed-powder particles and the substrate in the cold-gas dynamic-spray process, Appl. Surf. Sci. 219, 211-227 (2003).

[43] R. Drehmann, T. Grund, T. Lampke, B. Wielage, K. Manygoats, T. Schucknecht, et al, Interface characterization and bonding mechanisms of cold gas-sprayed Al coatings on ceramic substrates, J. Therm. Spray Techn. 24, 92-99 (2015).

[44] K. Kim, M. Watanabe, K. Mitsuishi, K. Iakoubovskii and S. Kuroda, Impact bonding and rebounding between kinetically sprayed titanium particle and steel substrate revealed by high-resolution electron microscopy, Appl. Phys. 42, 065304 (2009).

[45] Y. Xie, S.Yin, C. Chen, M.P. Planche, H. Liao and R. Lupoi, New insights into the coating/substrate interfacial bonding mechanism in cold spray. Scripta Mater. 125, 1-4 (2016). 
[46] Z. Arabgol, M.V. Vidaller, H. Assadi, F. Gärtner and T. Klassen, Influence of thermal properties and temperature of substrate on the quality of cold-sprayed deposits. Acta Mater. 127, 287-301 (2017).

[47] J.G. Lee, D.Y. Kim, B. Kang, D. Kim, H.E. Song, J. Kim, et al, Nickel-copper hybrid electrodes self-adhered onto a silicon wafer by supersonic cold-spray, Acta Mater. 93, 156-163 (2015).

[48] M.V. Vidaller, A. List, F. Gaertner, T. Klassen, S. Dosta and J.M. Guilemany, Single impact bonding of cold sprayed Ti-6Al-4V powders on different substrates, J. Therm. Spray Techn. 24, 644-658 (2015).

[49] G. Bae, Y. Xiong, S. Kumar, K. Kang and C. Lee, General aspects of interface bonding in kinetic sprayed coatings, Acta Mater. 56, 4858-4868 (2008).

[50] P.C. King, C. Busch, T. Kittel-Sherri, M. Jahedi and S. Gulizia, Interface melding in cold spray titanium particle impact, Surf. Coat. Techn. 239,191-199 (2014).

[51] T.S. Price, P.H. Shipway, D.G. McCartney, E. Calla and D. Zhang, A method for characterizing the degree of inter-particle bond formation in cold sprayed coatings, J. Therm. Spray Techn. 16, 566-570 (2007).

[52] T. Hussain, D.G. McCartney, P.H. Shipway and D. Zhang, Bonding mechanisms in cold spraying: the contributions of metallurgical and mechanical components, J. Therm. Spray Techn. 18, 364-379 (2009).

[53] R. Huang, W. Ma and H. Fukanuma, Development of ultra-strong adhesive strength coatings using cold spray, Surf. Coat. Techn. 258, 832-841 (2014).

[54] P. Coddet, C. Verdy, C. Coddet, F. Debray and F. Lecouturier, Mechanical properties of thick 304L stainless steel deposits processed by He cold spray, Surf. Coat. Techn. 277, 74-80 (2015).

[55] K.H. Ko, J.O. Choi and H. Lee, Intermixing and interfacial morphology of cold-sprayed Al coatings on steel, Mater. Lett. 136, 45-47 (2014).

[56] W.Y. Li, C.J. Li and G.J. Yang, Effect of impact-induced melting on interface microstructure and bonding of cold-sprayed zinc coating, Appl. Surf. Sci. 257, 1516-1523 (2010).

[57] W.Y. Li, C. Zhang, X. Guo, C.J. Li, H. Liao, C. Coddet, Study on impact fusion at particle interfaces and its effect on coating microstructure in cold spraying, Appl. Surf. Sci. 254, 517-526 (2007).

[58] S. Guetta, M.H. Berger, F. Borit, V. Guipont, M. Jeandin, M. Boustie, et al, Influence of particle velocity on adhesion of cold-sprayed splats, J. Therm. Spray Techn. 18, 331-342 (2009).

[59] G. Bae, S. Kumar, S. Yoon, K. Kang, H. Na, H.J. Kim and C. Lee, Bonding features and associated mechanisms in kinetic sprayed titanium coatings, Acta Mater. 57, 5654-5666 (2009).

[60] S. Yoon, G. Bae, Y. Xiong, S. Kumar, K. Kang and J.J. Kim , Strain-enhanced nanocrystallization of a CuNiTiZr bulk metallic glass coating by a kinetic spraying process, Acta Mater. 57, 6191-6199 (2009).

[61] R. Huang and H. Fukanuma, Study of the influence of particle velocity on adhesive strength of cold spray deposits, J. Therm. Spray Techn. 21, 541-549 (2012).

[62] J. Akedo, Aerosol deposition method for fabrication of nano crystal ceramic layer, Mater. Sci. Forum. 449, 43-48 (2004).

[63] D.M. Chun and S.H. Ahn, Deposition mechanism of dry sprayed ceramic particles at room temperature using a nano-particle deposition system, Acta Mater. 59, 2693-2703 (2011).

[64] C.J. Li, W.Y. Li and H. Liao, Examination of the critical velocity for deposition of particles in cold spraying, J. Therm. Spray Techn. 15, 212-222 (2006).

[65] C.J. Li, H.T. Wang, Q. Zhang, G.J. Yang, W.Y. Li and H.L. Liao, Influence of spray materials and their surface oxidation on the critical velocity in cold spraying, J. Therm. Spray Techn. 19, 95-101 (2010).

[66] W.Y. Li, C.J. Li and H.L. Liao, Significant influence of particle surface oxidation on deposition efficiency, interface microstructure and adhesive strength of cold-sprayed copper coatings, Appl. Surf. Sci. 256, 4953-4958 (2010).

[67] T. Schmidt, F. Gärtner, H. Assadi and H. Kreye, Development of a generalized parameter window for cold spray deposition, Acta Mater. 54, 729-742 (2006).

[68] J.H. Lee, J.S. Kim, S.M. Shin and C.H. Lee, Effect of particle temperature on the critical velocity for particle deposition by kinetic spraying, Proceedings of the 2006 International Thermal Spray Conference, May 15-18, 2006, (Seattle, USA), ASM International, 233-238 (2006).

[69] J. Lee, S. Shin, H Kim and C. Lee, Effect of gas temperature on critical velocity and deposition characteristics in kinetic spraying, Appl. Surf. Sci. 253, 3512-3520 (2007).

[70] S. Yin, X. Wang, X. Suo, H. Liao, Z. Guo, W. Li, et al, Deposition behavior of thermally softened copper particles in cold spraying, Acta Mater. 61, 5105-5118 (2013).

[71] M. Yu, W.Y. Li, F.F. Wang, X.K. Suo and H.L. Liao, Effect of particle and substrate preheating on particle deformation behavior in cold spraying, Surf. Coat. Techn. 220, 174-178 (2013).

[72] Y. Watanabe, C. Yoshida, K. Atsumi, M. Yamada and M. Fukumoto, Influence of substrate temperature on adhesion strength of cold-sprayed coatings, J. Therm. Spray Techn. 24, 86-91 (2015).

[73] A. Sova, S. Grigoriev, A. Kochetkova and I. Smurov, Influence of powder injection point position on efficiency of powder preheating in cold spray: Numerical study, Surf. Coat. Techn. 242, 226-231 (2014).

[74] T. Schmidt, H. Assadi, F. Gärtner, H. Richter, T. Stoltenhoff, H. Kreye. et al, From particle acceleration to impact and bonding in cold spraying, J. Therm. Spray Techn. 18, 794-808 (2009). 
[75] D.E. Wolfe, T.J. Eden, J.K. Potter, A.P. Jaroh, Investigation and characterization of Cr3C2-based wear-resistant coatings applied by the cold spray process, J. Therm. Spray Techn. 15, 400-412 (2006).

[76] M. Yu, W.Y. Li, X.K. Suo and H.L. Liao, Effects of gas temperature and ceramic particle content on microstructure and microhardness of cold sprayed SiCp/Al 5056 composite coatings, Surf. Coat. Techn. 220, 102-106 (2013).

[77] S. Shin, S. Yoon, Y. Kim and C. Lee, Effect of particle parameters on the deposition characteristics of a hard/soft-particles composite in kinetic spraying, Surf. Coat. Techn. 201, 3457-3461 (2006).

[78] S.V. Klinkov, V.F. Kosarev, A.A. Sova and I. Smurov, Calculation of particle parameters for cold spraying of metal-ceramic mixtures, J. Therm. Spray Techn. 18, 944-956 (2009).

[79] S.V. Klinkov, V.F. Kosarev, A.A. Sova, I. Smurov, Deposition of multicomponent coatings by cold spray, Surf. Coat. Techn. 202, 5858-5862 (2008).

[80] S. Kikuchi, S. Yoshino, M. Yamada, M. Fukumoto and K. Okamoto, Microstructures and thermal properties of cold-sprayed Cu-Cr composite coatings, J. Therm. Spray Techn. 22, 926-931 (2013).

[81] S. Shin, Y. Xiong, Y. Ji, H.J. Kim and C. Lee, The influence of process parameters on deposition characteristics of a soft/hard composite coating in kinetic spray process, Appl. Surf. Sci. 254, 2269-2275 (2008).

[82] A. Sova, V.F. Kosarev, A. Papyrin and I. Smurov, Effect of ceramic particle velocity on cold spray deposition of metal-ceramic coatings, J. Therm. Spray Techn. 20, 285-291 (2011).

[83] A. Sova, A. Papyrin and I Smurov, Influence of ceramic powder size on process of cermet coating formation by cold spray, J. Therm. Spray Techn. 18, 633-641 (2009).

[84] P.H. Gao, Y.G. Li, C.J. Li, G.J. Yang and C.X. Li, Influence of powder porous structure on the deposition behavior of cold-sprayed WC-12Co coatings, J. Therm. Spray Techn. 17, 742-749 (2008).

[85] A. Shkodkin, A. Kashirin, O. Klyuev and T. Buzdygar, Metal particle deposition stimulation by surface abrasive treatment in gas dynamic spraying, J. Therm. Spray Techn. 15, 382-386 (2006).

[86] N. Cinca, M. Barbosa, S. Dosta, J.M. Guilemany, Study of Ti deposition onto Al alloy by cold gas spraying, Surf. Coat. Techn. 205, 1096-1102 (2010).

[87] X.M. Meng, J.B. Zhang, J. Zhao, Y.L. Liang and Y.J. Zhang, Influence of gas temperature on microstructure and properties of cold spray 304SS coating, J. Mater. Sci. Techn. 27, 809-815 (2011).

[88] Y. Tao, T. Xiong, C. Sun, H. Jin, H. Du and T. Li, Effect of $\alpha-\mathrm{Al}_{2} \mathrm{O}_{3}$ on the properties of cold sprayed $\mathrm{Al} / \alpha-\mathrm{Al}_{2} \mathrm{O}_{3}$ composite coatings on AZ91D magnesium alloy, Appl. Surf. Sci. 256, 261-266 (2009).

[89] N. Bala, H. Singh, J. Karthikeyan and S. Prakash, Cold spray coating process for corrosion protection: a review, Surf. Eng. 30, 414-421 (2014).

[90] Z.B. Zhao, B.A. Gillispie, J.R. Smith. Coating deposition by the kinetic spray process. Surf. Coat. Techn. 200, 4746-4754 (2006).

[91] H.X. Hu, S.L. Jiang, Y.S. Tao, T.Y. Xiong and Y.G. Zheng. Cavitation erosion and jet impingement erosion mechanism of cold sprayed $\mathrm{Ni}-\mathrm{Al}_{2} \mathrm{O}_{3}$ coating. Nucl. Eng. Des. 241, 4929-4937 (2011).

[92] B.S. DeForce, T.J. Eden and J.K. Potter. Cold spray Al-5\%Mg coatings for the corrosion protection of magnesium alloys. Therm. Spray. Techn. 20, 1352-1358 (2011).

[93] N. Bala, H. Singh and S. Prakash. High temperature corrosion behavior of cold spray Ni-20Cr coating on boiler steel in molten salt environment at $900^{\circ} \mathrm{C}$. Therm. Spray. Techn. 19, 110-118 (2010).

[94] W.Y. Li, G. Zhang, H.L. Liao and C. Coddet. Characterizations of cold sprayed TiN particle reinforced Al2319 composite coating. Mater. Process. Techn. 202, 508-513 (2008).

[95] K. Spencer, D.M. Fabijanic and M.X. Zhang. The use of $\mathrm{Al}-\mathrm{Al}_{2} \mathrm{O}_{3}$ cold spray coatings to improve the surface properties of magnesium alloys. Surf. Coat. Techn. 204, 336-344 (2009).

[96] X.K. Suo, Q.L. Suo, W.Y. Li, M.P. Planche and H.L. Liao. Effects of SiC volume fraction and particle size on the deposition behavior and mechanical properties of cold-sprayed AZ91D/SiCp composite coatings. Therm. Spray. Techn. 23, 91-97 (2014).

[97] H.T. Wang, C.J. Li, G.J. Yang and C.X. Li. Cold spraying of Fe/Al powder mixture: Coating characteristics and influence of heat treatment on the phase structure. Appl. Surf. Sci. 255, 2538-2544 (2008).

[98] H.Y. Lee, S.H. Jung, S.Y. Lee and K.H. Ko. Alloying of cold-sprayed Al-Ni composite coatings by post-annealing. Appl. Surf. Sci. 53, 3496-3502 (2007).

[99] N. Bala, H. Singh and S. Prakash. Characterization and high-temperature oxidation behavior of cold-sprayed Ni-20Cr and Ni-50Cr coatings on boiler steels. Metal. Mater. Trans. 42, 3399-3416 (2011).

[100] S. Cho, K. Takagi, H. Kwon, D. Seo, K. Ogawa and K. Kikuchi. Multi-walled carbon nanotube-reinforced copper nanocomposite coating fabricated by low-pressure cold spray process. Surf. Coat. Techn. 6, 488-494 (2012).

[101] G. Rolland, P. Sallamand, V. Guipont, M. Jeandin, E. Boller and C. Bourda. Damage study of cold-sprayed composite materials for application to electrical contacts. Therm. Spray. Techn. 21, 758-772 (2012).

[102] J. Morimoto, T. Onoda, Y. Sasaki, N. Abe. Improvement of solid cold sprayed $\mathrm{TiO}_{2}-\mathrm{Zn}$ coating with direct diode laser. 73, 527-532 (2004). 
[103] M. Gardon, C. Fernández-Rodríguez, D.G. Sousa, J.M. Doña-Rodríguez, S. Dosta, I.G. Cano and J.M. Guilemany. Photocatalytic activity of nanostructured anatase coatings obtained by cold gas spray. Therm. Spray. Techn. 23, 1135-1141 (2014).

[104] J. Wang, X. Zhou, L. Lu, D. Li, P. Mohanty and Y. Wang. Microstructure and properties of Ag/SnO2 coatings prepared by cold spraying. Surf. Coat. Techn. 236, 224-229 (2013).

[105] Y. Liu, Z. Dang, Y. Wang, J. Huang and H. Li. Hydroxyapatite/graphene-nanosheet composite coatings deposited by vacuum cold spraying for biomedical applications: Inherited nanostructures and enhanced properties. Carbon. 67, 250-259 (2014).

[106] Y. Liu, J. Huang and H. Li. Nanostructural characteristics of vacuum cold-sprayed hydroxyapatite/graphene-nanosheet coatings for biomedical applications. Therm. Spray. Techn. 23, 1149-1156 (2014).

[107] A.C. Noorakma, H. Zuhailawati, V. Aishvarya and B.K. Dhindaw. Hydroxyapatite-coated magnesium-based biodegradable alloy: cold spray deposition and simulated body fluid studies. Mater. Eng. Perform. 22, 2997-3004 (2013).

[108] A.M. Vilardell, N. Cinca, A. Concustell, S. Dosta, I.G. Cano and J.M. Guilemany. Cold spray as an emerging technology for biocompatible and antibacterial coatings: state of art. Mater. Sci. 50, 4441-4462 (2015).

[109] C. Lee and J. Kim. Microstructure of Kinetic Spray Coatings: A review. Therm. Spray. Techn. 24, 592-610 (2015).

[110] V.K. Champagne. The Cold Spray Materials Deposition Process: Fundamentals and Applications. Elsevier Science (2007).

[111] J. Pattison, S. Celotto, R. Morgan, M. Bray and W. O’Neill. Cold gas dynamic manufacturing: A non-thermal approach to freeform fabrication. Mach. Tools. Manuf. 47, 627-634 (2007).

[112] R.H. Morgan, C.J. Sutcliffe, J. Pattison, M. Murphy, C. Gallagher, A. Papworth, et al. Cold gas dynamic manufacturing-A new approach to near-net shape metal component fabrication. MRS Proceedings, Cambridge University Press, USA (2002).

[113] Department of defense manufacturing process standard. Materials deposition, cold spray, MIL-STD-3021 (2008).

[114] N.N. Das, M. Rucker, B. Pilsner and A. Reynolds. Near net shape composite airfoil leading edge protective strips made using cold spray deposition. U.S. Patent Application No. US20110129351 A1 (2009).

[115] ASTM F2792-12A, Standard Terminology for Additive Manufacturing Tech-nologies, ASTM International, West Conshohocken, PA (2012)

[116] Z.Y. Xiu, W.S. Yang, R.H. Dong, M. Hussain, L.T. Jiang, Y.X. Liu, et al. Microstructure and mechanical properties of 45 vol.\% SiCp/7075Al composite. Mater. Sci. Techn. 31, 930-934 (2015).

[117] X.P. Li, C.Y. Liu, K. Luo, M.Z. Ma and R.P. Liu. Hot deformation behaviour of SiC/AA6061 composites prepared by spark plasma sintering. Mater. Sci. Techn. 32, 291-297 (2016).

[118] D.R. Ni, J.J. Wang and Z.Y. Ma. Shape memory effect, thermal expansion and damping property of friction stir processed NiTip/Al composite. Mater. Sci. Techn. 32, 162-166 (2016).

[119] W.Y. Li, G. Zhang, C. Zhang, O. Elkedim, H. Liao and C. Coddet. Effect of ball milling of feedstock powder on microstructure and properties of TiN particle-reinforced al alloy-based composites fabricated by cold spraying. Therm. Spray. Techn. 17, 316-322 (2008).

[120] W.Y. Li, G. Zhang, X.P. Guo, H.L. Liao and C. Coddet. Characterizations of cold-sprayed TiN particle-reinforced Al alloy-based composites-from structures to tribological behaviour. Adv. Eng. Mater. 9, 577-583 (2007).

[121] A. Moridi, S.M. Hassani-Gangaraj, M. Guagliano and M. Dao. Cold spray coating: review of material systems and future perspectives. Surf. Eng. 36, 369-395 (2014).

[122] V. Shukla, G.S. Elliott, B.H. Kear and L.E. McCandlish. Hyperkinetic deposition of nanopowders by supersonic rectangular jet impingement. Scripta. Mater. 44, 2179-2182 (2001).

[123] S.Yin, Z. Zhang, E.J. Ekoi, J.J. Wang, D.P. Dowling and Nicolosi, Novel cold spray for fabricating graphene-reinforced metal matrix composites. Mater. Lett. 196, 172-175 (2017).

[124] F.S.D. Silva, J. Bedoya, S. Dosta, N. Cinca, I.G. Cano and J.M.Guilemany, Corrosion characteristics of cold gas spray coatings of reinforced aluminum deposited onto carbon steel. Corros. Sci. 114, 57-71 (2017).

[125] A. Kashirin, O. Klyuev, T. Buzdygar and A. Shkodkin. DYMET technology evolution and application. Thermal Spray: Global Coating Solutions. 141-145 (2007).

[126] X. Guozhi, Z. Jingxian, L. Yijun, W. Keyu, M. Xiangyin and L. Pinghua. Effect of laser remelting on corrosion behavior of plasma-sprayed Ni-coated WC coatings. Mater. Sci. Eng. 460, 351-356 (2007).

[127] K.J. Hodder, H. Izadi, A.G. McDonald and A.P. Gerlich. Fabrication of aluminum-alumina metal matrix composites via cold gas dynamic spraying at low pressure followed by friction stir processing. Mater. Sci. Eng. 556, 114-121 (2012). 
[128] C.J. Huang, W.Y. Li, Z.H. Zhang, M.S. Fu, M.P. Planche, H.L. Liao, et al. Modification of a cold sprayed

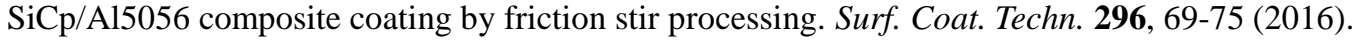

[129] Q. Wang, K. Spencer, N. Birbilis and M.X. Zhang. The influence of ceramic particles on bond strength of cold spray composite coatings on AZ91 alloy substrate. Surf. Coat. Techn. 205, 50-56 (2010).

[130] M. Yandouzi, P. Richer and B. Jodoin. SiC particulate reinforced Al-12Si alloy composite coatings produced by the pulsed gas dynamic spray process: microstructure and properties. Surf. Coat. Techn. 203, 3260-3270 (2009).

[131] M. Yu, X.K. Suo, W.Y. Li, Y.Y. Wang and H.L. Liao. Microstructure, mechanical property and wear performance of cold sprayed Al5056/SiCp composite coatings: Effect of reinforcement content. Appl. Surf. Sci. 289, 188-196 (2014).

[132] X.L. Zhou, S.J. Mou, X.K. Wu and J.S. Zhang. Deposition behavior of mixed binary metallic powders in cold spraying process. Appl. Surf. Sci. 257, 10628-10633 (2011).

[133] W.Y. Li, K. Yang, D.D. Zhang and X.L. Zhou. Interface behavior of particles upon impacting during cold spraying of $\mathrm{Cu} / \mathrm{Ni} / \mathrm{Al}$ mixture. Mater. Design. 95, 237-246 (2016).

[134] C.J. Li, W.Y. Li, Y.Y. Wang, G.J. Yang and H. Fukanuma. A theoretical model for prediction of deposition efficiency in cold spraying. Thin. Solid.Films. 489, 79-85 (2005).

[135] D.L. Zhang. Processing of advanced materials using high-energy mechanical milling. Prog. Mater. Sci. 49, 537-560 (2004).

[136] D. Poirier, J.G. Legoux, R.A. Drew and R. Gauvin. Consolidation of $\mathrm{Al}_{2} \mathrm{O}_{3} / \mathrm{Al}$ nanocomposite powder by cold spray. Therm. Spray. Techn. 20, 275-284 (2011).

[137] Q. Zhang, C.J. Li, X.R. Wang, Z.L. Ren, C.X. Li and G.J. Yang. Formation of NiAl intermetallic compound by cold spraying of ball-milled Ni/Al alloy powder through post annealing treatment. Therm. Spray. Techn. 17, 715-720 (2008).

[138] M. Yandouzi, A.J. Böttger, R.W.A. Hendrikx, M. Brochu, P. Richer, A. Charest, et al. Microstructure and mechanical properties of $\mathrm{B}_{4} \mathrm{C}$ reinforced Al-based matrix composite coatings deposited by CGDS and PGDS processes. Surf. Coat. Techn. 205, 2234-2246 (2010).

[139] H.K. Kang and S.B. Kang. Tungsten/copper composite deposits produced by a cold spray. Scripta. Mater. 49, 1169-1174 (2003).

[140] S. Tria, O. Elkedim, W.Y. Li and H.L. Liao. Ball milled Ni-Ti powder deposited by cold spraying. Alloy. Compd. 483, 334-336 (2009).

[141] X.T. Luo, C.X. Li, F.L. Shang, G.J. Yang, Y.Y. Wang and C.J. Li. WC-Co composite coating deposited by cold spraying of a core-shell-structured WC-Co powder. Therm. Spray. Techn. 24, 100-107 (2015).

[142] W.Y. Li and C.J. Li. Characterization of cold-sprayed nanostructured Fe-based alloy. Appl. Surf. Sci. 256, 2193-2198 (2010).

[143] H.T. Wang, C.J. Li, G.J. Yang, C.X. Li, Q. Zhang and W.Y. Li. Microstructural characterization of cold-sprayed nanostructured FeAl intermetallic compound coating and its ball-milled feedstock powders. Therm. Spray. Techn. 16, 669-676 (2007).

[144] L. Ajdelsztajn, J.M. Schoenung, B. Jodoin and G.E. Kim. Cold spray deposition of nanocrystalline aluminum alloys. Metall. Mater .Trans A. 36, 657-666 (2005).

[145] P. Richer, B. Jodoin and L. Ajdelsztajn. Substrate roughness and thickness effects on cold spray nanocrystalline Al-Mg coatings. Therm. Spray. Techn. 15, 246-254 (2006).

[146] R. Ghelichi, S. Bagherifard, D. Mac Donald, M. Brochu, H. Jahed, B. Jodoin, et al. Fatigue strength of Al alloy cold sprayed with nanocrystalline powders. Fatigue. 65, 51-57 (2014).

[147] Y.Y. Zhang, X.K. Wu, H. Cui and J.S. Zhang. Cold-spray processing of a high density nanocrystalline aluminum alloy 2009 coating using a mixture of as-atomized and as-cryomilled powders. Therm. Spray. Techn. 20, 1125-1132 (2011).

[148] D.J. Woo, B. Sneed, F. Peerally, F.C. Heer, L.N. Brewer, J.P. Hooper, et al. Synthesis of nanodiamond-reinforced aluminum metal composite powders and coatings using high-energy ball milling and cold spray. Carbon. 63, 404-415 (2013).

[149] S.R. Bakshi, V. Singh, K. Balani, D.G. McCartney, S. Seal and A. Agarwal. Carbon nanotube reinforced aluminum composite coating via cold spraying. Surf. Coat. Techn. 202, 5162-5169 (2008).

[150] T.C. Jen, L. Li, W. Cui, Q. Chen and X. Zhang. Numerical investigations on cold gas dynamic spray process with nano-and microsize particles. Heat. Mass. Tran. 48, 4384-4396 (2005).

[151] K.J. Hodder, J.A. Nychka and A.G. McDonald. Comparison of $10 \mu \mathrm{m}$ and $20 \mathrm{~nm} \mathrm{Al}-\mathrm{Al}_{2} \mathrm{O}_{3}$ metal matrix composite coatings fabricated by low-pressure cold gas dynamic spraying. Therm. Spray. Techn. 23, 839-848 (2014).

[152] P.S. Phani, V. Vishnukanthan and G. Sundararajan. Effect of heat treatment on properties of cold sprayed nanocrystalline copper alumina coatings. Acta. Mater. 55, 4741-4751 (2007).

[153] H.J. Kim, C.H. Lee and S.Y. Hwang. Superhard nano WC-12\% Co coating by cold spray deposition. Mat. Sci. Eng. 391, 243-248 (2005). 
[154] H.J. Kim, C.H. Lee and S.Y. Hwang. Fabrication of WC-Co coatings by cold spray deposition. Surf Coat Techn. 191, 335-340 (2005).

[155] M. Yandouzi, L. Ajdelsztajn and B. Jodoin. WC-based composite coatings prepared by the pulsed gas dynamic spraying process: Effect of the feedstock powders. Surf. Coat. Techn. 202, 3866-3877 (2008).

[156] S. Mirzamohammadi, H. Khorsand and M. Aliofkhazraei, Effect of different organic solvents on electrodeposition and wear behavior of Ni-alumina nanocomposite coatings. Surf. Coat. Techn. 313, 202-213 (2017).

[157] S. Dosta, M. Couto and J.M. Guilemany. Cold spray deposition of a WC-25Co cermet onto Al7075-T6 and carbon steel substrates. Acta. Mater. 61, 643-652 (2013).

[158] C.J. Li, G.J. Yang, P.H. Gao, J. Ma, Y.Y. Wang and C.X. Li. Characterization of nanostructured WC-Co deposited by cold spraying. Therm. Spray. Techn. 16, 1011-1020 (2007).

[159] P.H. Gao, C.J. Li, G.J. Yang, Y.G. Li and C.X. Li. Influence of substrate hardness transition on built-up of nanostructured WC-12Co by cold spraying. Appl. Surf. Sci. 256, 2263-2268 (2010).

[160] W.Y. Li, C. Zhang, H.L. Liao, C.J. Li and C. Coddet. Characterizations of cold-sprayed nickel-alumina composite coating with relatively large nickel-coated alumina powder. Surf. Coat. Techn. 202, 4855-4860 (2008).

[161] W.Y. Li, C.J. Huang, M. Yu, D.X. Liu, Y. Feng and H.L. Liao. Investigation of high temperature oxidation behavior and tribological performance on cold sprayed nickel-alumina composite coating. Surf. Coat. Techn. 239, 95-101 (2014).

[162] C. Feng, V. Guipont, M. Jeandin, O. Amsellem, F. Pauchet, R. Saenger, et al. B 4 C/Ni composite coatings prepared by cold spray of blended or CVD-coated powders. Therm. Spray. Techn. 21, 561-570 (2012).

[163] H Na, G Bae, S Shin, S Kumar, H Kim and C Lee, Advanced deposition characteristics of kinetic sprayed bronze/diamond composite by tailoring feedstock properties. Compo. Sci. Technol. 69, 463-468 (2009).

[164] H.J. Kim, D.H. Jung, J.H. Jang and C.H. Lee, Assessment of metal/diamond composite coatings by cold spray deposition, In. Thermal Spray 2006-Building on 100 Years of Success; 15-18 (2006).

[165] S. Yin, Y. Xie, J. Cizek, E.J. Ekoi, T. Hussain, D.P. Dowling and R. Lupoi, Advanced diamond-reinforced metal matrix composites via cold spray: Properties and deposition mechanism. Compos. part b-Eng. 113, 44-54 (2017).

[166] S. Grigoriev, A. Okunkova, A. Sova, P. Bertrand and I. Smurov, Cold Spraying: From process fundamentals towards advanced applications, Surf. Coat. Techn. 268, 77-84 (2015).

[167] J.S. Kim, Y.S. Kwon, O.I. Lomovsky, D.V. Dudina, V.F. Kosarev and S.V. Klinkov, Cold spraying of in situ produced $\mathrm{TiB}_{2}-\mathrm{Cu}$ nanocomposite powders, Compos. Sci. Technol. 67, 2292-2296 (2007).

[168] G.J. Yang, P.H. Gao, C.X. Li and C.J. Li, Simultaneous strengthening and toughening effects in WC-(nanoWC-Co), Scripta Mater. 66, 777-780 (2012).

[169] A.S. Ang. C.C. M Berndt and P. Cheang, Deposition effects of WC particle size on cold sprayed WC-Co coatings, Surf. Coat. Techn. 205, 3260-3267 (2011).

[170] H.Y. Lee, S.H. Jung, S.Y. Lee, Y.H. You and K.H. Ko, Correlation between $\mathrm{Al}_{2} \mathrm{O}_{3}$ particles and interface of $\mathrm{Al}-\mathrm{Al}_{2} \mathrm{O}_{3}$ coatings by cold spray, Appl. Surf. Sci. 252, 1891-1898 (2005).

[171] H.Y. Lee, Y.H. Yu, Y.C. Lee, Y.P. Hong and K.H. Ko, Cold spray of $\mathrm{SiC}$ and $\mathrm{Al}_{2} \mathrm{O}_{3}$ with soft metal incorporation: a technical contribution, J. Therm. Spray. Techn. 13, 184-189 (2004).

[172] Y. Danlos, S. Costil, X. Guo, H. Liao and C. Coddet, Ablation laser and heating laser combined to cold spraying, Surf. Coat. Tech. 205, 1055-1059 (2010).

[173] C.J. Li, X.K. Suo, G.J. Yang and C.X. Li, Influence of annealing on the microstructure and wear performance of diamond/NiCrAl composite coating deposited through cold spraying, Mater. Sci. Forum. 638, 894-899 (2010).

[174] J.M. Miguel, J.M. Guilemany and S. Dosta, Effect of the spraying process on the microstructure and tribological properties of bronze-alumina composite coatings, Surf. Coat. Techn. 205, 2184-2190 (2010).

[175] J. Wu, Y. Tao, H. Jin, M. Li, T. Xiong and C. Sun, Friction and wear properties of cold gas dynamic sprayed $\alpha-\mathrm{Al}_{2} \mathrm{O}_{3}-\mathrm{Al}$ composite coatings, J. Coat. 1-7 (2013).

[176] M. Yu, W.Y. Li, H. Chen, X.K. Suo and H.L. Liao, Effect of matrix/reinforcement combination on cold sprayed coating deposition behavior, Surf. Eng. 30, 796-800 (2014).

[177] E. Sansoucy, P. Marcoux, L Ajdelsztajn and B Jodoin, Properties of SiC-reinforced aluminum alloy coatings produced by the cold gas dynamic spraying process, Surf. Coat. Techn. 202, 3988-3996 (2008).

[178] A. Shkodkin, A. Kashirin, O. Klyuev and T. Buzdygar, Metal particle deposition stimulation by surface abrasive treatment in gas dynamic spraying, J. Therm. Spray Techn. 15, 382-386 (2006).

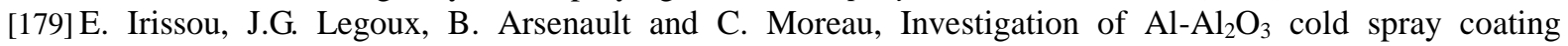
formation and properties, J. Therm. Spray Techn. 16, 661-668 (2007).

[180] H. Bu, M. Yandouzi, C. Lu, D. MacDonald and B. Jodoin, Cold spray blended $A \mathrm{Al} \mathrm{Mg}_{17} \mathrm{Al}_{12}$ coating for corrosion protection of AZ91D magnesium alloy, Surf. Coat. Techn. 207, 155-162 (2012).

[181] K. Spencer, D.M. Fabijanic and M.X. Zhang, The influence of $\mathrm{Al}_{2} \mathrm{O}_{3}$ reinforcement on the properties of 
stainless steel cold spray coatings, Surf. Coat. Techn. 206, 3275-3282 (2012).

[182] H. Koivuluoto and P. Vuoristo, Effect of ceramic particles on properties of cold-sprayed $\mathrm{Ni}-20 \mathrm{Cr}+\mathrm{Al}_{2} \mathrm{O}_{3}$ coatings, J. Therm. Spray Techn. 18, 555-562 (2009).

[183] H. Koivuluoto, A. Milanti, G. Bolelli, L. Lusvarghi and P. Vuoristo, High-pressure cold-sprayed Ni and Ni-Cu coatings: improved structures and corrosion properties, J. Therm. Spray Techn. 23, 98-103 (2014).

[184] M. Yu, H. Chen, W.Y. Li, X.K. Suo, H.L. Liao, Building-up process of cold-sprayed Al5056/In718 composite coating, J. Therm. Spray Techn. 24, 579-586 (2015).

[185] W.Y. Li, C. Yang and H. Liao, Effect of vacuum heat treatment on microstructure and microhardness of cold-sprayed TiN particle-reinforced Al alloy-based composites, Mater. Design, 32, 388-394 (2011).

[186] H Koivuluoto and P Vuoristo, Structural analysis of cold-sprayed nickel-based metallic and metallic-ceramic coatings, J. Therm. Spray Techn. 19, 975-989 (2010).

[187] C.J. Huang and W.Y. Li, Strengthening mechanism and metal/ceramic bonding interface of cold sprayed TiNp/A15356 deposits, Surf. Eng. 32, 663-669 (2016).

[188] H. Assadi, T. Klassen, F. Gärtner, T. Nanbu, Y. Kawashita, Y. Uehara and Kanagawa, Modelling of impact and bonding of inhomogeneous particles in cold spraying, In: International Thermal Spray Conference 2014, Barcelona/Spain, May 21-23, 203-207 (2014).

[189] H Li, X Li, M Sun, H Wang and G Huang, Corrosion resistance of cold-sprayed Zn-50Al coatings in seawater, J. Chin. Soc. Corros. Prot. 30, 62-66 (2010). [in Chinese]

[190] Y.M. Jin, J.H. Cho, D.Y. Park, J.H. Kim and K.A. Lee. Manufacturing and macroscopic properties of cold sprayed Cu-In coating material for sputtering target. J. Therm. Spray Techn. 20, 497-507 (2011).

[191] X.K. Wu, X.L. Zhou, H Cui, X. Zheng and J.S. Zhang, Deposition behavior and characteristics of cold-sprayed Cu-Cr composite deposits, J. Therm. Spray Techn. 21, 792-799 (2012).

[192] T. Novoselova, S. Celotto, R. Morgan, P. Fox and W. O'neill, Formation of TiAl intermetallics by heat treatment of cold-sprayed precursor deposits, J. Alloy Compd. 436, 69-77 (2007).

[193] W.Y. Li, C. Zhang, X.P. Guo, G. Zhang, H.L. Liao, C.J. Li, et al, Effect of standoff distance on coating deposition characteristics in cold spraying, Mater. Design, 29, 297-304 (2008).

[194] E. Sansoucy, G.E. Kim, A.L. Moran and B. Jodoin, Mechanical characteristics of Al-Co-Ce coatings produced by the cold spray process, J. Therm. Spray Techn. 16, 651-660 (2007).

[195] H.Y. Lee, S.H. Jung, S.Y. Lee, K.H. Ko, Fabrication of cold sprayed Al-intermetallic compounds coatings by post annealing, Mat. Sci. Eng. A. 433, 139-143 (2006).

[196] K Spencer and MX Zhang, The use of kinetic metallization to form intermetallic reinforced composite coatings by post-spray heat treatment, Surf. Coat. Techn. 203, 3019-3025 (2009).

[197] X.P. Guo, G. Zhang, W.Y. Li, Y. Gao, H.L. Liao and C Coddet, Investigation of the microstructure and tribological behavior of cold-sprayed tin-bronze-based composite coatings, Appl. Surf. Sci. 255, 3822-3828 (2009).

[198] H. Singh, T.S. Sidhu, J. Karthikeyan, S.B.S. Kalsi, Evaluation of characteristics and behavior of cold sprayed Ni-20Cr coating at elevated temperature in waste incinerator plant, Surf Coat Techn. 261, 375-384 (2015).

[199] H. Singh, T.S. Sidhu, S.B.S. Kalsi and J. Karthikeyan, Hot corrosion behavior of cold-sprayed Ni-50Cr coating in an incinerator environment at $900^{\circ} \mathrm{C}$, J. Therm. Spray Techn. 24, 570-578 (2015).

[200] Y. Wang , B. Normand, N. Mary, M. Yu and H. Liao, Microstructure and corrosion behavior of cold sprayed $\mathrm{SiC}_{\mathrm{p}} / \mathrm{Al} 5056$ composite coatings. Surf. Coat. Techn. 251, 264-275 (2014).

[201]F. Sevillano, P. Poza, C.J. Múnez, S. Vezzù, S. Rech and A. Trentin, Cold-sprayed Ni-Al2O3 coatings for applications in power generation industry. J. Therm. Spray Techn. 22, 772-782 (2013).

[202] Z.T. Xiao, X.B. Li, J. Wang, G.S. Huang and X. Zhou. Effect of heat treatment on tribological properties of cold-sprayed Cu-20\%Al2O3 composite coatings. Mater. Rev. 26, 76-80 (2012). [in Chinese]

[203] N.M. Melendez, V.V. Narulkar, G.A. Fisher and A.G. McDonald, Effect of reinforcing particles on the wear rate of low-pressure cold-sprayed WC-based MMC coatings. Wear 306, 185-195 (2013).

[204] C.J. Li and G.J. Yang, Relationships between feedstock structure, particle parameter, coating deposition, microstructure and properties for thermally sprayed conventional and nanostructured WC-Co. Int. J. Refract Met. Hard Mater 39, 2-17 (2013).

[205] M. Couto, S. Dosta and J.M. Guilemany, Comparison of the mechanical and electrochemical properties of WC-17 and 12Co coatings onto Al7075-T6 obtained by high velocity oxy-fuel and cold gas spraying. Surf. Coat. Techn. 268, 180-189 (2015).

[206] M. Couto, S. Dosta, J. Fernández and J.M. Guilemany, Comparison of the mechanical and electrochemical properties of WC-25Co coatings obtained by high velocity oxy-fuel and cold gas spraying. J. Therm. Spray Techn. 23, 1251-1258 (2014).

[207]Z.S. Fan, S.S. Wang and Z.D. Zhang, Microstructures and properties of nano-structural wc-12co coatings deposited by ac-hvaf. Rare Metal Mat. Eng. 46, 923-927 (2017).

[208] Z. Geng, S. Hou, G. Shi, D. Duan and S. Li, Tribological behaviour at various temperatures of wc-co 
coatings prepared using different thermal spraying techniques. Tribol. Int. 104, 36-44 (2016).

[209] G. Bolelli, T. Börner, A. Milanti, L. Lusvarghi, J. Laurila and H. Koivuluoto, Tribological behavior of hvofand hvaf-sprayed composite coatings based on fe-alloy+wc-12\% co. Surf. Coat. Techn. 248, 104-112 (2014).

[210] Q. Wang, S. Zhang, Y. Cheng, J. Xiang, X. Zhao and G. Yang,. Wear and corrosion performance of wc-10co4cr coatings deposited by different hvof and hvaf spraying processes. Surf. Coat. Techn. 218, 127-136 (2013).

[211] Q. Wang, N. Birbilis, H. Huang and M.X. Zhang, Microstructure characterization and nanomechanics of cold-sprayed pure Al and Al-Al2O3 composite coatings. Surf. Coat. Techn. 232, 216-223 (2013).

[212] X. Zhou and P. Mohanty, Electrochemical behavior of cold sprayed hydroxyapatite/titanium composite in Hanks' solution. Electrochim Acta. 65,134-140 (2012).

[213] J.M. Shockley, S. Descartes, E. Irissou, J.G. Legoux and R.R. Chromik, Third body behavior during dry sliding of cold-sprayed Al-Al2O3 composites: in situ tribometry and microanalysis. Tribol Lett 54, 191-206 (2014).

[214] J.M. Shockley, S. Descartes, P. Vo, E. Irissou and R.R. Chromik, The influence of $\mathrm{Al} 2 \mathrm{O} 3$ particle morphology on the coating formation and dry sliding wear behavior of cold sprayed Al-Al2O3 composites. Surf. Coat. Tech. 270, 324-333 (2015).

[215] J.M. Shockley, H.W. Strauss, R.R. Chromik, N. Brodusch, R. Gauvin, E. Irissou and J.G. Legoux, In situ tribometry of cold-sprayed Al-Al2O3 composite coatings. Surf. Coat. Techn. 215, 350-356 (2013).

[216] K.I. Triantou, D.I. Pantelis, V. Guipont and M. Jeandin, Microstructure and tribological behavior of copper and composite copper+alumina cold sprayed coatings for various alumina contents. Wear 336, 96-107 (2015).

[217] R.B. Heimann, J.I. Kleiman, E. Litovsky, S. Marx, R. Ng, S. Petrov, et al, High-pressure cold gas dynamic (CGD)-sprayed alumina-reinforced aluminum coatings for potential application as space construction material. Surf. Coat. Techn. 252, 113-199 (2014).

[218] O. Meydanoglu, B. Jodoin and E.S. Kayali, Microstructure, mechanical properties and corrosion performance of $7075 \mathrm{Al}$ matrix ceramic particle reinforced composite coatings produced by the cold gas dynamic spraying process. Surf. Coat. Techn. 235, 108-116 (2013).

[219] V.C. Srivastava, A. Schneider, V. Uhlenwinkel and K. Bauckhage, Spray processing of 2014-Al+SiCp composites and their property evaluation. Mater Sci Eng: A 412, 19-26 (2005).

[220] G.L. Eesley, A. Elmoursi and N. Patel, Thermal properties of kinetic spray Al-SiC metal-matrix composite. J. Mater Res. 18, 855-860 (2003).

[221] W. Liu, M. Yu and W.Y.Li, Effect of vacuum heat treatment on microstructure and microhardness of Ni-Al2O3 composite coating prepared by cold spraying. Hot Working Technol, 39(42), 196-198 ( 2010). [in Chinese]

[222] M. Watanabe, M. Komatsu and S. Kuroda, WC-Co/Al multilayer coatings by warm spray deposition. $J$. Therm. Spray Techn. 21, 597-560 (2012).

[223] N. Cinca, A. List, A. Gärtner, J.M. Guilemany and T. Klassen, Influence of spraying parameters on cold gas spraying of iron aluminide intermetallics. Surf. Coat. Techn. 268 99-107 (2015).

[224] Y. Zhou, G.J. Yang, H.D. Wang, G. Li and C.J. Li, Effect of annealing treatment on formation of intermetallic phase in cold-sprayed Ni/Ti mechanical alloying coating. Trans. Chin. Weld Inst. 31, 45-48 (2010). [in Chinese]

[225] A. Bacciochini, S. Bourdon-Lafleur, C. Poupart, M. Radulescu and B. Jodoin, Ni-Al nanoscale energetic materials: phenomena involved during the manufacturing of bulk samples by cold spray. J. Therm. Spray Techn. 23, 1142-1148 (2014).

[226] L.Y. Kong, L. Shen, B. Lu, R. Yang, X.Y. Cui, T.F. Li, et al, Preparation of TiAl3-Al composite coating by cold spray and its high temperature oxidation behavior. J. Therm. Spray Techn. 19, 1206-1210 (2010).

[227] P. Podrabinnik, S. Grigoriev and I. Shishkovsky, Laser post annealing of cold-sprayed Al/Alumina-Ni composite coatings. Surf. Coat. Techn. 271, 265-268 (2015).

[228] G.J.Yang, S.N. Zhao, C.X. Li and C.J. Li, Effect of phase transformation mechanism on the microstructure of cold-sprayed Ni/Al-Al2O3 composite coatings during post-spray annealing treatment. J. Therm. Spray Techn. 22, 398-405 (2013).

[229] T. Novoselova, P. Fox, R. Morgan and W. O'Neill, Experimental study of titanium/aluminium deposits produced by cold gas dynamic spray. Surf. Coat. Techn. 200, 2775-2783 (2006).

[230] J. Cizek, O. Man, P. Roupcova, K. Loke and I. Dlouhy, Oxidation performance of cold spray Ti-Al barrier coated $\gamma$-TiAl intermetallic substrates. Surf. Coat. Techn. 268, 85-89 (2015).

[231] J Wang, L. Kong, T. Li and T. Xiong. Oxidation behavior of thermal barrier coatings with a TiAl3 bond coat on $\gamma$-TiAl alloy. J. Therm. Spray Techn. 24, 467-475 (2015).

[232] H.T. Wang, C.J. Li, G.C. Ji and G.J. Yang, Annealing effect on the intermetallic compound formation of cold sprayed Fe/Al composite coating. J. Therm. Spray Techn. 21, 571-577 (2012). 
[233] V. Jan, J. Čupera and J. Cizek, On the search for producing intermetallics by diffusion reaction of cold spray bulk deposits. Surf. Coat. Techn. 268, 216-223 (2015).

[234] K.H. Ko, H. Lee and J.O. Choi, Effect of Sn particle size on the intermetallic compound formations of cold sprayed Sn-Ni coatings. Appl Surf. Sci. 257, 2970-2977 (2011).

[235] X.J. Ning, J.H. Jang, H.J. Kim, C.J. Li, and C. Lee, Cold spraying of Al-Sn binary alloy: Coating characteristics and particle bonding features. Surf. Coat. Techn. 202, 1681-1687 (2008).

[236] K. Spencer and M.X. Zhang. Heat treatment of cold spray coatings to form protective intermetallic layers. Scripta. Mater 61, 44-47 (2009).

[237] T. Chandanayaka and F, Azarmi. Investigation on the effect of reinforcement particle size on the mechanical properties of the cold sprayed Ni-Ni3Al composites. J. Mater. Eng. Perform. 23, 1815-1822 (2014).

[238] F. Azarmi, X.W. Tangpong and T. Chandanayaka, Investigation on mechanical properties of cold sprayed $\mathrm{Ni}-\mathrm{Ni}_{3} \mathrm{Al}$ composites. Surf. Eng. 31, 832-839 (2015).

[239] M. Cherigui, W. Li, R. Hamzaoui, V. Ji, N. Fenineche and C. Coddet, Microstructure and magnetic properties of FeSiBNbCu-Al cold spray coatings, Eur. Phys. J. Appl. Phys. 43, 79-86 (2008).

[240] T.V. Steenkiste, Kinetic sprayed rare earth iron alloy composite coatings, J. Therm. Spray Techn. 15, 501-506 (2006).

[241] J. Mondoux, B. Jodoin, L. Ajdelsztajn, J.M. Schoenung and G.E. Kim, Nanostructured aluminum coatings produced using cold spraying technology, In: ITSC 2004: International Thermal Spray Conference 2004: Advances in Technology and Application; p. 347-351 (2004).

[242] J. Liu, H. Cui, X. Zhou, X. Wu and J. Zhang, Nanocrystalline copper coatings produced by cold spraying, Met. Mater. Int. 18, 121-128 (2012).

[243] L. Ajdelsztajn, B. Jodoin and J.M. Schoenung, Synthesis and mechanical properties of nanocrystalline Ni coatings produced by cold gas dynamic spraying, Surf. Coat. Techn. 201, 1166-72 (2006).

[244] J.A. Gan and C.C. Berndt, Nanocomposite coatings: thermal spray processing, microstructure and performance, Int. Mater. Rev. 60, 195-244 (2015).

[245] M.R. Rokni, C.A. Widener, A.T. Nardi and V.K. Champagne, Nano crystalline high energy milled $5083 \mathrm{Al}$ powder deposited using cold spray, Appl. Surf. Sci. 305, 797-804 (2014).

[246] L. Ajdelsztajn, A. Zuniga, B. Jodoin and E.J. Lavernia, Cold-Spray processing of a nanocrystalline Al-Cu-Mg-Fe-Ni alloy with Sc, J. Therm. Spray Techn. 15, 184-90 (2006).

[247] A. Bacciochini, M.I. Radulescu, Y. Charron-Tousignant, J. Van Dyke, B. Jodoin and M. Nganbe, Enhanced reactivity of mechanically-activated nano-scale gasless reactive materials consolidated via the cold-spray technique, In: Shock compression of condensed matter-2011: proceedings of the conference of the American physical society topical group on shock compression of condensed matter. AIP Publishing, p. 543-546 (2012).

[248] S.B. Pitchuka, D. Lahiri, G. Sundararajan and A. Agarwal, Scratch-induced deformation behavior of cold-sprayed aluminum amorphous/nanocrystalline coatings at multiple load scales, J. Therm. Spray Techn. 23, 502-513 (2013).

[249] M. Kumar, H. Singh, N. Singh, S.M. Hong, I.S. Choi and J.Y. Suh, Development of nano-crystalline cold sprayed Ni-20Cr coatings for high temperature oxidation resistance, Surf. Coat Techn. 266, 122-33 (2015).

[250] N. Kaur, M. Kumar, S.K. Sharma, D.Y. Kim, S. Kumar and N.M. Chavan, Study of mechanical properties and high temperature oxidation behavior of a novel cold-spray Ni-20Cr coating on boiler steels, Appl. Surf. Sci. 328, 13-25 (2015).

[251] N.M. Melendez and A.G. McDonald, Development of WC-based metal matrix composite coatings using low-pressure cold gas dynamic spraying, Surf. Coat Tech. 214, 101-109 (2013).

[252] D. Lioma, N. Sacks and I. Botef, Cold gas dynamic spraying of WC-Ni cemented carbide coatings, Int. J. Refract Met. Hard Mater. 49, 365-73 (2015).

[253] G.J. Yang, P.H. Gao, C.X. Li and C.J. Li, Mechanical property and wear performance dependence on processing condition for cold-sprayed WC-(nanoWC-Co), Appl. Surf. Sci. 332, 80-88 (2015).

[254] Y. Chen, S.R. Bakshi and A. Agarwal, Correlation between nanoindentation and nanoscratch properties of carbon nanotube reinforced aluminum composite coatings, Surf. Coat Techn. 204, 2709-2715 (2010).

[255] K. Kang, G. Bae, J. Won and C. Lee, Mechanical property enhancement of kinetic sprayed Al coatings reinforced by multi-walled carbon nanotubes, Acta Mater. 60, (2012) 5031-5039.

[256] E.J.T. Pialago and C.W. Park, Cold spray deposition characteristics of mechanically alloyed Cu-CNT composite powders, Appl. Surf. Sci. 308, 63-74 (2014).

[257] E.J.T. Pialago, O.K. Kwon and C.W. Park, Nucleate boiling heat transfer of R134a on cold sprayed CNT-Cu composite coatings, Appl. Therm. Eng. 56, 112-119 (2013).

[258] E.J. Pialago, X.R. Zheng, K.A. Ada, O.K. Kwon, D.A. Cha and C.W. Park, A study on the effects of ceramic content of CNT/metal composite surface coatings fabricated by cold spray for boiling heat transfer enhancement, In: ASME 2012 third international conference on micro/nanoscale heat and mass transfer. 
American Society of Mechanical Engineers 2012; p. 391-398.

[259] P. Cavaliere, A. Perrone and A. Silvello, Mechanical and microstructural behavior of nanocomposites produced via cold spray, Compos. Part B: Eng. 67, 326-331 (2014).

[260] M. Yandouzi, H. Bu, M. Brochu and B. Jodoin, Nanostructured Al-based metal matrix composite coating production by pulsed gas dynamic spraying process, J. Therm. Spray Techn. 21, 609-619 (2012).

[261] E.P. Georgiou, S. Achanta, S. Dosta, J. Fernández, P. Matteazzi and J. Kusinski, Structural and tribological properties of supersonic sprayed $\mathrm{Fe}-\mathrm{Cu}-\mathrm{Al}-\mathrm{Al}_{2} \mathrm{O}_{3}$ nanostructured cermets, Appl. Surf. Sci. 275, 142-147 (2013).

[262] H. Park, J. Heo, F. Cao, J. Kwon, K. Kang and G. Bae, Deposition behavior and microstructural features of vacuum kinetic sprayed aluminum nitride, J. Therm. Spray Techn. 22, 882-891 (2013).

[263] J. Akedo, Room temperature impact consolidation (RTIC) of fine ceramic powder by aerosol deposition method and applications to microdevices, J. Therm. Spray Techn. 17, 181-198 (2008).

[264] D. Hanft, J. Exner, M. Schubert, T. Stöcker, P. Fuierer and R. Moos, An overview of the aerosol deposition method: Process fundamentals and new trends in materials applications, J. Ceram. Sci. Technol. 6, 147-182 (2015)..

[265] J. Akedo, Aerosol deposition of ceramic thick films at room temperature: densification mechanism of ceramic layers, J. Am. Ceram. Soc. 89, 1834-1839 (2006).

[266] F. Cao, H. Park, J. Heo, J. Kwon and C.Lee, Effect of process gas flow on the coating microstructure and mechanical properties of vacuum kinetic-sprayed TiN layers, J. Therm. Spray Techn. 22, 1109-1119 (2013).

[267] F. Cao, H. Park, G. Bae, J. Heo and C. Lee, Microstructure evolution of titanium nitride film during vacuum kinetic spraying, J. Am. Ceram. Soc. 96, 40-43 (2013).

[268] H. Park, J. Kwon, I. Lee and C. Lee, Shock-induced plasticity and fragmentation phenomena during alumina deposition in the vacuum kinetic spraying process, Scripta Mater. 100, $44-47$ (2015).

[269] S.Q. Fan, G.J. Yang, C.J. Li, G.J. Liu, C.X. Li and L.Z. Zhang, Characterization of microstructure of nano- $\mathrm{TiO}_{2}$ coating deposited by vacuum cold spraying, J. Therm. Spray Techn. 15, 513-517 (2006).

[270] S.Q. Fan, C.J. Li, G.J. Yang, L.Z. Zhang, J.C. Gao and Y.X. Xi, Fabrication of nano- $\mathrm{TiO}_{2}$ coating for dye-sensitized solar cell by vacuum cold spraying at room temperature, J. Therm. Spray Techn. 16, 893-897 (2007).

[271] G.J. Yang, C.J. Li, K.X. Liao, X.L. He, S. Li and S.Q. Fan, Influence of gas flow during vacuum cold spraying of nano-porous $\mathrm{TiO}_{2}$ film by using strengthened nanostructured powder on performance of dye-sensitized solar cell, Thin Solid Films, 519, 4709-4713 (2011).

[272] M. Yamada, H. Isago, H. Nakano and M. Fukumoto, Cold spraying of $\mathrm{TiO}_{2}$ photocatalyst coating with nitrogen process gas, J. Therm. Spray Techn. 19, 1218-1223 (2010).

[273] Y.Y. Wang, Y. Liu, G.J. Yang, J.J. Feng and K. Kusumoto, Effect of Microstructure on the electrical properties of nano-structured TiN coatings deposited by vacuum cold spray, J. Therm. Spray Techn. 19, 1231-1237 (2010).

[274] Y.Y. Wang, Y. Liu, C.J. Li, G.J. Yang and K. Kusumoto, Electrical and mechanical properties of nano-structured TiN coatings deposited by vacuum cold spray, Vacuum, 86, 953-959 (2012).

[275] J. Heo, P. Sudhagar, H. Park, W. Cho, Y.S. Kang and C. Lee, Room temperature synthesis of highly compact $\mathrm{TiO}_{2}$ coatings by vacuum kinetic spraying to serve as a blocking layer in polymer electrolyte-based dye-sensitized solar cells, J. Therm. Spray Techn. 24, 328-337 (2015).

[276] Y. Liu, Y.Y. Wang, G.J. Yang, J.J. Feng and K. Kusumoto, Effect of nano-sized TiN additions on the electrical properties of vacuum cold sprayed SiC coatings, J. Therm. Spray Techn. 19, 1238-1243 (2001).

[277] D.Y. Kim, B.N. Joshi, J.J. Park, J.G. Lee, Y.H. Cha, T.Y. Seong, et al, Graphene-titania films by supersonic kinetic spraying for enhanced performance of dye-sensitized solar cells, Ceram. Int. 40, 11089-11097 (2014).

[278] J. Exner, P. Fuierer and R. Moos, Aerosol codeposition of Ceramics: mixtures of Bi2O3-TiO2 and Bi2O3-V2O5, J. Am. Ce-ram. Soc. 98, 717-723 (2014)

[279] S. Krebs, F. Gärtner and T. Klassen, Cold spraying of $\mathrm{Cu}-\mathrm{Al}$-Bronze for cavitation protection in marine environments, J. Therm. Spray Techn. 24, 126-135 (2015).

[280] W.Y. Li, H.L.Liao and H.T.Wang, Cold spraying of light alloys. In: Dong H. Surface engineering of light alloys: aluminum, magnesium and titanium alloys, Woodhead Publishing, p.242-293 (2010).

[281] W.Y. Li, X.P. Guo, C. Verdy, L. Dembinski, H.L. Liao and C. Coddet, Improvement of microstructure and property of cold-sprayed Cu-4at.\%Cr-2at.\% Nb alloy by heat treatment, Scripta Mater. 55, 327-330 (2006).

[282] Q. Zhang, C.J. Li, C.X. Li, G.J. Yang and S.C. Lui, Study of oxidation behavior of nanostructured NiCrAlY bond coatings deposited by cold spraying, Surf. Coat. Techn. 202, 3378-3384 (2008).

[283] Zhang Q., Li C.J., Li Y., Zhang S.L., Wang X.R., Yang G.J., et al. Thermal failure of nanostructured thermal barrier coatings with cold-sprayed nanostructured NiCrAlY bond coat, J. Therm. Spray Techn. 17, 838-845 (2008).

[284] V. Crespo, I.G. Cano, S. Dosta and J.M. Guilemany, The influence of feedstock powders on the CGS 
deposition efficiency of bond coats for TBCs, J. Alloy Compd. 622, 394-401 (2015).

[285] A. Bonadei and T. Marrocco, Cold sprayed MCrAlY+X coating for gas turbine blades and vanes, Surf. Coat Tech. 242, 200-206 (2014).

[286] W.S. Rathod, A.S. Khanna, J. Karthikeyan and R.C. Rathod, Oxidation and corrosion behaviour of CoNiCrAlY bond coats, Surf. Eng. 30, 432-442 (2014).

[287] X.P. Guo, G. Zhang, W.Y. Li, L. Dembinski, Y. Gao, H.L. Liao, et al, Microstructure, microhardness and dry friction behavior of cold-sprayed tin bronze coatings, Appl. Surf. Sci. 254, 1482-1488 (2007).

[288] N. Cinca and J.M. Guilemany, Structural and properties characterization of stellite coatings obtained by cold gas spraying, Surf. Coat Techn. 220, 90-97 (2013).

[289] N. Cinca, E. López, S. Dosta and J.M. Guilemany, Study of stellite-6 deposition by cold gas spraying, Surf. Coat. Techn. 232, 891-898 (2013).

[290] G.P. Wagner, D.B. Allen and B.B. Seth, Abradable coating applied with cold spray technique. U.S. Patent Application No. 6365222 B1; (2002).

[291] V.K. Champagne and D.J. Helfritch, Mainstreaming cold spray-push for applications, Surf. Eng. 30, 396-403 (2014).

[292] G.J. Yang, C.J. Li, F. Han, W.Y. Li and A. Ohmori, Low temperature deposition and characterization of TiO2 photocatalytic film through cold spray, Appl. Surf. Sci. 254, 3979-3782 (2008).

[293] M. Gardon, H. Melero, N. Garcia-Giralt, S. Dosta, I.G. Cano and J.M. Guilemany, Enhancing the bioactivity of polymeric implants by means of cold gas spray coatings, J. Biomed Mater. Res. B 102, 1537-1543 (2014).

[294] M. Gardon and J.M. Guilemany, Milestones in functional titanium dioxide thermal spray coatings: a review, J. Therm. Spray Techn. 23, 577-595 (2014).

[295] M. Gardon, A. Concustell, S. Dosta, N. Cinca, I.G. Cano and J.M. Guilemany, Improved bonding strength of bioactive cermet cold gas spray coatings, Mater. Sci. Eng.: C 45, 117-121 (2014).

[296] P. Coddet, C. Verdy, C. Coddet and F. Debray, On the mechanical and electrical properties of copper-silver and copper-silver-zirconium alloys deposits manufactured by cold spray. Mater. Sci. Eng. A 662, 72-79 (2016).

[297] C.Z. Xu, Q.J. Wang, M.S. Zheng, J.W. Zhu, J.D. Li, M.Q. Jia and Z.Z. Du, Microstructure and properties of ultra-fine grain $\mathrm{Cu}-\mathrm{Cr}$ alloy prepared by equal-channel angular pressing, Mater. Sci. Eng. A 459, 303-308 (2007).

[298] N.M. Chavan, M. Ramakrishna, P.S. Phani, D.S. Rao and G. Sundararajan, The influence of process parameters and heat treatment on the properties of cold sprayed silver coatings, Surf. Coat. Technol. 205, 4798-4807 (2011)

[299] J. Villafuerte, Recent trends in cold spray technology: looking at the future, Surf. Eng. 26, 393-394 (2010).

[300] J.C. Lee, H.J. Kang, W.S. Chu and S.H. Ahn, Repair of damaged mold surface by cold-spray method, CIRP Annals-Manufacturing Technology, 56, 577-580 (2007).

[301] P.D. Eason, J.A. Fewkes, S.C. Kennett, T.J. Eden, K. Tello, M.J. Kaufman, et al. On the characterization of bulk copper produced by cold gas dynamic spray processing in as fabricated and annealed conditions, Mater. Sci. Eng.: A 528, 8174-8178 (2011).

[302] S.A. Miller, F.C. Dary, M. Gaydos and G. Rozak, Methods of manufacturing large-area sputtering targets by cold spray, U.S. Patent Application No. 8703233 B2; 2014.

[303] Y. Cormier, P. Dupuis, B. Jodoin and A. Corbeil, Mechanical properties of cold gas dynamic-sprayed near-net-shaped fin arrays, J. Therm. Spray Techn. 24, 476-488 (2015).

[304] http://www.plasma.co.jp/en/products/coldspray.html

[305] M. Faccoli, G. Cornacchia, D. Maestrini, G.P. Marconi and R. Roberti, Cold spray repair of martensitic stainless steel components, J. Therm. Spray Techn. 23, 1270-1280 (2014).

[306] V. Champagne and D. Helfritch, Critical Assessment 11: Structural repairs by cold spray. Mater. Sci. Tech. 31, 627-634 (2015).

[307] M. Yandouzi, S. Gaydos, D. Guo, R. Ghelichi and B. Jodoin, Aircraft skin restoration and evaluation, J. Therm. Spray Techn. 23, 1281-1290 (2014).

[308] J. Villafuerte, Current and future applications of cold spray technology, Met. Finish 108, 37-39 (2010).

[309] N. Matthews, Supersonic particle deposition (SPD) cutting edge technology for corrosion protection and damaged metallic component recover, In: Proceedings 2010 SDE symposium program "Design Engineering in a SRP Environment". RAAF Williams, Melbourne, Australia, p. 24-25 (2010).

[310] J.S. Zhang, Studying of repairing UH-60 helicopter by cold spraying of Air Force Research Laboratory, Inf. Surf. Eng. 1, 18-18 (2012). [in Chinese].

[311] L.X. Chen and M. Chen, The coating performance of cold spraying $\mathrm{Cu}-\mathrm{Zn}-\mathrm{Al}_{2} \mathrm{O}_{3}$ for repairing the waterway corrosion area of steyr engine, Mach. Des. Res. 29, 69-74 (2013). [in Chinese].

[312] S. Rech, A. Trentin, S. Vezzù, E. Vedelago, J.G. Legoux and E. Irissou, Different cold spray deposition strategies: single-and multi-layers to repair aluminium alloy components, J. Therm. Spray Techn. 23, 
1237-1250 (2014).

[313] V.K. Champagne, The repair of magnesium rotorcraft components by cold spray, J. Fail Anal. Prev. 8, 164-175 (2008).

[314] J. Villafuerte and D. Wright, Practical cold spray success: Repair of Al and Mg alloy aircraft components, Adv. Mater. Process, 168, 53-55 (2010).

[315] Y. Hu, F. Renteria, C. Cahoon and M.Floyd Method for repairing titanium alloy components, U.S. Patent Application No. US 2006/0045785 A1; 2004.

[316] R. Jones, N. Matthews, C.A. Rodopoulos, K. Cairns and S. Pitt, On the use of supersonic particle deposition to restore the structural integrity of damaged aircraft structures, Int. J. Fatigue, 33, 1257-1267 (2011) 